\title{
Complutum
}

ISSN: 1131-6993

\section{La gestión del patrimonio desde el ámbito municipal: nuevas perspectivas de futuro para Aroche (Huelva)}

\author{
Nieves Medina Rosales ${ }^{1}$ y Juan M. Campos Carrasco ${ }^{2}$
}

Recibido: 21/03/2021 / Aceptado: 13/08/2021

Resumen. El mundo rural se enfrenta en los últimos tiempos a una amenaza real, que pone en peligro no sólo un modo de vida, sino también el patrimonio histórico-arqueológico atesorado durante siglos. Esta amenaza, especialmente grave en la llamada "España vaciada", motivó hace décadas el inicio de políticas europeas específicas, que aún no han tenido eco a nivel nacional o autonómico, a pesar de que el problema es cada vez más evidente. Esta pérdida de población y el riesgo de pérdida de su patrimonio determinaron el surgimiento en Aroche (Huelva) en 2004 del Proyecto Patrimonio, una iniciativa municipal de gestión integral del patrimonio, cuyos objetivos se enmarcan en el desarrollo equilibrado de los cuatro eslabones de la cadena de valor: investigación, protección, conservación y socialización. Objetivos éstos orientados a promover un desarrollo social, cultural y económico sostenible referidos a un municipio rural de interior con apenas 3.000 habitantes. Con una trayectoria ininterrumpida de diecisiete años, el Proyecto Patrimonio ha conseguido conocer, proteger, conservar y reintegrar a la sociedad gran parte de su patrimonio, además de generar un amplio desarrollo cultural y social, y una incipiente reactivación económica con la generación de empleo directo y el aumento del turismo.

Palabras Clave: patrimonio, gestión, rural, conservación, socialización, Aroche.

\section{[en] Heritage management from the municipal level: new prospects for the future for Aroche (Huelva).}

Abstract. The rural world is facing a real threat in recent times, which endangers not only a way of life, but also the historical-archaeological heritage treasured for centuries. This threat, more popular as "emptied Spain", motivated the initiation of specific European policies decades ago, which have not yet had an echo at the national or regional level, despite the fact that the problem is increasingly evident. The loss of population and the risk of loss of heritage motivate the emergence in Aroche (Huelva) in 2004 of the Heritage Project, a municipal initiative of integral management of heritage, whose objectives are framed in the four links of the value chain: research, protection, conservation and socialization of heritage. These objectives are linked to promoting sustainable social, cultural and economic development of a rural inland municipality of just 3,000 inhabitants. After more than sixteen years of uninterrupted history, the Heritage Project has managed to know, protect, conserve and deliver to society a large part of its heritage, in addition to generating broad cultural and social development, and incipient economic development with the generation of employment and the increase in tourism.

Keywords: heritage, management, rural, conservation, socialization, Aroche.

Sumario. Introducción. El Proyecto Patrimonio. Investigación. Protección. Conservación. Socialización. Financiación del proyecto. Logros del proyecto. Conclusiones. Bibliografía.

Como citar: Medina Rosales, N.; Campos Carrasco, J. M. (2021): La gestión del patrimonio desde el ámbito municipal: nuevas perspectivas de futuro para Aroche (Huelva). Complutum, 32(2): 365-385. 


\section{Introducción}

Aroche es un municipio rural de interior, localizado en Andalucía occidental, en la Sierra de Huelva, en la frontera hispanolusa, y dentro del Parque Natural Sierra de Aracena y Picos de Aroche, al que presta parte de su denominación. Con un término municipal de $499,50 \mathrm{~km}^{2}$, y una población de 3.054 habitantes, resulta ser el tercer municipio más poblado de la Comarca Serrana y el segundo municipio de la provincia de Huelva con mayor patrimonio histórico-arqueológico documentado. Gran parte de su núcleo urbano fue protegido mediante su declaración como Conjunto Histórico, destacando en él un trazado amurallado de 1,2 kms., correspondiente a las épocas medieval y moderna; un castillo de origen almohade construido sobre los restos de un castro prerromano; un convento de la Orden de los Jerónimos del siglo XVII, algunas casas palacio de los siglo XVII y XVIII, y un extenso caserío popular adaptado a las curvas de nivel de los dos cerros sobre los cuales se asentó la población. El Conjunto Histórico se complementa con la ciudad romana de Arucci y la medieval ermita de San Mamés, enclave arqueológico y monumental, ubicado a tan sólo unos $3 \mathrm{kms}$. En el resto del extenso término municipal más de cien yacimientos arqueológicos constatan la ocupación ininterrumpida de este territorio desde la Prehistoria a la actualidad.

El mundo rural se enfrenta a importantes retos, cuya resolución requiere de la implicación social y administrativa, y cuyas consecuencias pueden derivar en la pérdida no sólo de un modo de vida, sino de un patrimonio en el más extenso sentido del término, de valor incalculable, y cuya recuperación, quizás ya no sea posible. Aroche ha sufrido un descenso de población del $4,7 \%$ en los últimos diez años, y un $12,82 \%$ en los últimos veinte (Gráfico 1). Este índice podría no resultar alarmante si la edad media de la población en 2020 no fuese de 44'8 años y la tasa de población por encima de los 65 años del $20,7 \%$. Lo que unido a una tendencia significativamente desequilibrada entre nacimientos y defunciones (en 2017 por ejemplo, se produjeron 29 nacimientos y 41 defunciones) o la emigración a núcleos mayores, hacen que la amenaza del despoblamiento parezca más cercana.

Ante estas perspectivas de futuro, desde la administración municipal se apostó por políticas que beneficiaran el desarrollo socioeconómico y cultural, con proyectos que fijaran la población al territorio, reforzando las señas de identidad colectiva y propiciando una mayor interrelación entre los habitantes y el territorio. Dentro de estas políticas se enmarca el Proyecto Patrimonio (Medina 2020c; 2020d), pero también otras, como los esfuerzos por diversificar la economía potenciando una nueva agricultura, con cultivos de frutos rojos, principalmente arándano.

Cuatro cuestiones claves determinan al Ayuntamiento de Aroche en 2004 a iniciar un proyecto municipal de gestión integral del patrimonio histórico-arqueológico, concibiéndolo como un marco desde el cual poder desarrollar de forma equilibrada los cuatro eslabones básicos de la cadena de valor (Criado 1996a;

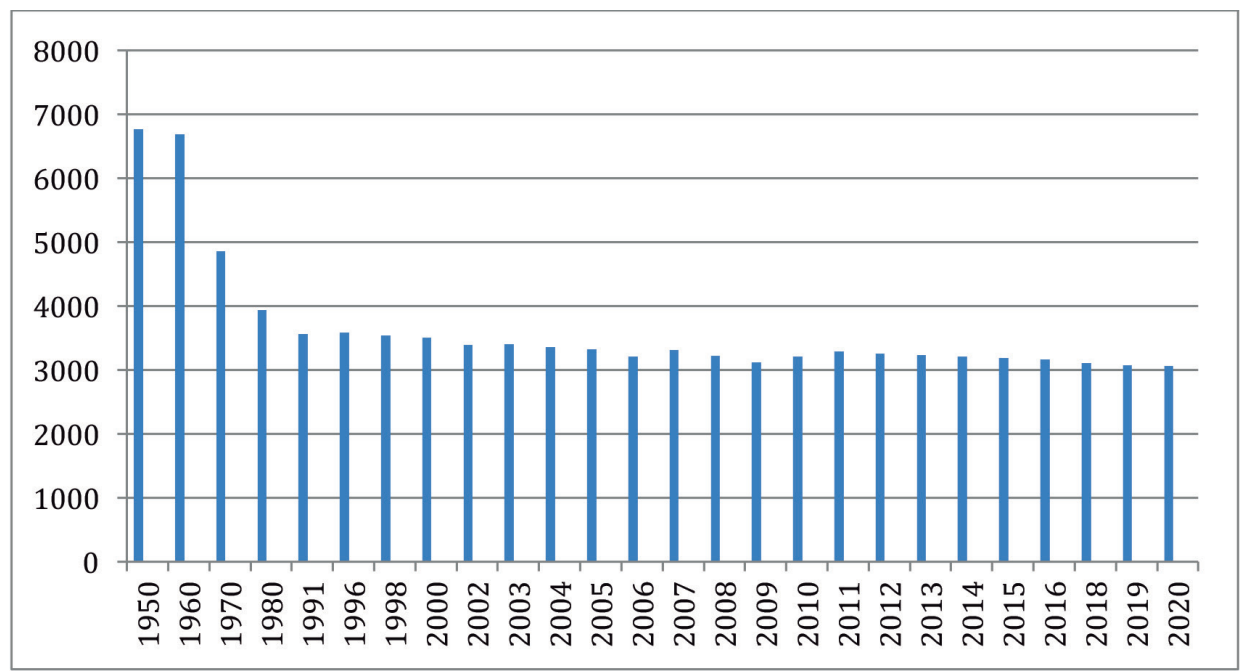

Gráfico 1. Estadística de población desde 1950 (Fuente: http://www.juntadeandalucia.es/ institutodeestadisticaycartografia/sima/ficha.htm?mun=21008). 
1996b): Investigación, Protección, Conservación y Socialización. La primera motivación fue la existencia en el municipio de un extenso e importante patrimonio histórico-arqueológico. La segunda, el mal estado de conservación que éste presentaba en 2003, seriamente amenazado. En tercer lugar, la necesidad de desarrollo socioeconómico y cultural de un municipio rural de interior con incipientes síntomas de despoblación. Y en cuarto lugar la llegada al gobierno municipal en 2003 de un nuevo equipo con sensibilidad hacia el patrimonio.

La falta de competencias en materia de patrimonio histórico, asumidas por las administraciones nacional y autonómica, hace que los Ayuntamientos, la administración más cercana opte o no por gestionar estos bienes, que pueden convertirse también en recursos culturales e incluso turísticos. No obstante, la legislación no les atribuye competencias que les obliguen a su mantenimiento, protección, conservación o socialización, siendo una elección personal o política la que por ahora impulsa proyectos de esta tipología desde el ámbito municipal.

En 2004 escaseaban los ejemplos de municipios andaluces embarcados en proyectos de gestión del patrimonio, y el Ayuntamiento de Aroche necesitaba contar con referentes claros que permitieran conocer los retos a los que se enfrentaba. Por ello, metodológicamente, el primer paso fue visitar y analizar algunos modelos con una larga trayectoria y logros importantes. El más cercano, aunque en el país luso, fue el caso de Mertola, un unicum con más de cuarenta años de desarrollo de su proyecto Mertola, Vila Museu, y con un reconocido prestigio nacional e internacional (Gómez 2008a; 2008b; 2017; Da Silva 2010; Gómez et al 2016: Torres 2003; Torres y Gómez 2007). El segundo ejemplo, también muy consolidado, fue el proyecto de gestión del patrimonio, social y territorial de Almedinilla, en la Subbética cordobesa (Muñiz 2002; 2007; 2008a; 2008b; 2008c; 2016). Ambos municipios tienen menos de 3.000 habitantes, están ubicados en zonas rurales de interior, se enfrentan a dificultades semejantes a las existentes en Aroche, y poseen un importante patrimonio históricoarqueológico susceptible de ser gestionado.

\section{El Proyecto Patrimonio}

El Proyecto se inicia en enero de 2004, siguiendo una sencilla metodología de trabajo:
1. Visitas para conocer ejemplos de gestión.

2. Análisis exhaustivo del estado del patrimonio.

3. Valoración de la urgencia de las intervenciones en función de las necesidades de conservación.

4. Definición y búsqueda de financiación.

5. Planificación de investigaciones y actuaciones de conservación y socialización a corto, medio y largo plazo.

6. Desarrollo anual de intervenciones y actuaciones.

Para la ejecución del Proyecto y también para el control urbanístico del municipio se creó una Oficina Municipal de Urbanismo y Patrimonio, dotada en la actualidad con un arquitecto, un arqueólogo, dos arquitectos técnicos, un abogado y un administrativo, además del personal de obras, mantenimiento, jardinería y turismo. Una importante dotación de personal y medios teniendo en cuenta que corresponde a un Ayuntamiento de un pueblo que apenas sobrepasa los 3.000 habitantes.

Desde 2004 a la actualidad se han llevado a cabo más de 130 intervenciones directas sobre el patrimonio, sin incluir investigaciones y actividades de difusión y socialización. El objetivo era desarrollar de forma equilibrada la cadena de valor, si bien, la socialización debió esperar a obtener los primeros resultados de las investigaciones, teniendo en cuenta que no se puede mostrar algo que no se conoce, además de poder garantizar su conservación antes de entregar el patrimonio al público (Medina 2018a; 2018b; 2020a, 2020b, 2020c, 2020d).

El Proyecto, expuesto como un caso práctico, ha ido evolucionando con la experiencia, y enriqueciéndose con el conocimiento de otros ejemplos de gestión, como Mérida (Alba 2009; 2014), Córdoba (Vaquerizo 2016; 2017), Écija (García-Dils y Ordóñez 2011; García Dils 2015), etc. Establecemos la existencia de dos fases dentro del desarrollo del proyecto. La primera fase denominada "de inicio" y comprendida entre 2004 y 2007; y una segunda fase "de madurez" desde 2008 a la actualidad. En la fase de inicio se establecen los objetivos y metodología, iniciándose un lento y constante trabajo de sensibilización destinado a la población local, con el objetivo de convertir el proyecto a largo plazo en una demanda social, que garantice la conservación del legado histórico-arqueológico. Las primeras intervenciones se destinaron a evitar problemas graves de conservación, pero 
también a mostrar los objetivos, y el cambio significativo que podría representar para el municipio. En la fase de madurez se multiplican las intervenciones, equilibrando los trabajos de investigación y conservación con los destinados a socializar el patrimonio, favoreciendo la consolidación del proyecto así como un mayor desarrollo social, cultural y económico.

En los últimos diecisiete años, se han realizado más de un centenar de intervenciones, incluyendo trabajos arqueológicos, restauraciones, consolidaciones y actividades de socialización. Esta publicación no tiene como objetivo el análisis de esos trabajos; sin embargo, es necesario aclarar que se ha investigado e intervenido en los principales monumentos, destacando el Castillo (Medina 2005; 2020d), las Murallas (Medina 2018a; 2018c), la Torre de San Ginés (Medina 2018a; 2018 c), la ciudad romana de Arucci (Bermejo y Campos 2009; 2011; 2013; y Medina 2013; etc.), la Ermita de San Mamés (Medina 2020d), el Convento de la Cilla (Medina 2018a; 2018b; 2020d), la Iglesia de la Asunción (Medina, González y Acedo e.p.) y otros muchos espacios y elementos del Conjunto Histórico (Medina 2010). Las investigaciones han permitido un amplio conocimiento de la romanización de este territorio y han generado un elevado número de publicaciones al respecto (Bermejo y Campos 2009; 2011; 2013), pero también la evolución histórica del núcleo urbano de Aroche ha sido objeto de estudio (Medina 2018a; 2018c; etc.). Se ha reforzado la protección en el Plan General de Ordenación Urbana y se ha realizado un constante mantenimiento para garantizar la conservación. Y por último, un amplio programa de socialización, a nivel local, científico, social, cultural y turístico ha completado el proceso.

A nivel general, se ha conseguido desde el ámbito local transformar el futuro del patrimonio, garantizando su conservación, pero también mejorando con ello el futuro del municipio: social, cultural y económicamente. Para lograr estos objetivos, se han realizado diferentes y numerosas acciones encuadradas en los principios de Investigación, Protección, Conservación y Socialización.

\section{Investigación}

Es el pilar principal que sustenta a todos los demás y el que otorga rigor científico e históri- co a cualquier acción enmarcada en la gestión. Es imprescindible conocer el patrimonio que se pretende gestionar; por lo que la investigación cobra el máximo protagonismo, asegurando el conocimiento científico e impulsando la transferencia de estos conocimientos mediante la metodología, técnicas y medios más adecuados. No se puede desligar "gestión" de “investigación” (Pérez-Juez 2010), ya que no puede haber gestión sin conocimiento, aunque de otra forma, sí es posible la investigación sin gestión. En esta tarea, cobra especial significación la excelente colaboración surgida entre el Ayuntamiento de Aroche y la Universidad de Huelva, a través del Grupo Vrbanitas Arqueología y Patrimonio. El Área de Arqueología de la Universidad de Huelva, ya por los años 90 del pasado siglo, comenzó a realizar investigaciones en la ciudad romana de Arucci; sin embargo, estos trabajos realizados de forma intermitente y sin un marco proyectual de colaboración sólo tendrían repercusión científica (Pérez et al 1997; 1999; 2002). El Proyecto ha propiciado que los trabajos de la Universidad cobren un significado mucho más amplio y sus resultados han influido de manera evidente en la cultura, la sociedad o la economía del lugar. La asociación del Ayuntamiento y el Grupo de Investigación Vrbanitas ha marcado, sobre todo en lo que al yacimiento arqueológico de Arucci se refiere, una forma de conjugar la investigación con el resto de eslabones de la cadena de valor (Campos, Medina y Bermejo 2017). El yacimiento ha pasado de estar abandonado a ser objeto en estos años de tres Proyectos Generales de Investigación, numerosas intervenciones puntuales, trabajos de consolidación y adecuación para las visitas, un mantenimiento diario, apertura al público estable desde 2004, publicaciones científicas en revistas y congresos especializados a nivel nacional e internacional (Bermejo 2014; Bermejo y Campos 2009; 2011; 2013; Bermejo et al 2014; Campos 2009; Campos et al 2013; etc.) y acciones de sensibilización y socialización, como prácticas para escolares del municipio, exposiciones, visitas guiadas, talleres, la edición de un cuadernillo pedagógico, visitas con recreación histórica o eventos como el Festival de Diana ( unas jornadas de cultura clásica vinculadas al yacimiento) (Medina e.p.b).

Si bien Arucci es uno de los ejes principales del plan de gestión, y gracias además a la Universidad se ha consolidado como uno de los yacimientos de mayor proyección de la pro- 
vincia, otros recursos también han sido objeto de investigaciones, generándose una valiosa información histórica. Los trabajos arqueológicos de apoyo a la restauración o los seguimientos arqueológicos de las obras en el Conjunto permitieron documentar una fase prerromana y romana republicana en el cerro ocupado por el castillo (Rivera y Romero 2005), la ocupación califal en la ladera baja de la población (Medina 2010), así como, la ocupación almohade en el entorno del castillo (Medina 2018c; Vidal et al e.p.), y hasta tres fases de la muralla medieval-moderna de la villa (Medina e.p.a).

\section{Protección}

A nivel municipal las herramientas que permiten una mayor protección del patrimonio histórico-arqueológico son limitadas. Aroche cuenta con cinco protecciones de máximo nivel, así como dos inscripciones genéricas colectivas, además de la Carta Arqueológica Municipal y la incorporación de sus datos al PGOU. El núcleo urbano, por su singularidad, fue protegido mediante el Real Decreto 2794/1980, de 4 de noviembre (BOE núm. 312, de 29 de diciembre de 1980), declarado Conjunto Histórico-Artístico, pasando a tener la consideración de Bien de Interés Cultural (BIC), de conformidad con la Disposición Adicional Primera de la Ley 16/1985, de 25 de junio, del Patrimonio Histórico Español. Esta delimitación abarcaba el castillo y la muralla artillera, declarados BIC por la Ley de 1947. Por el Decreto 288/2007, de 4 de diciembre (BOJA 2 de 3 de enero de 2008), la delimitación de 1980 fue modificada y ampliada.

Fuera del núcleo urbano, el yacimiento califal de La Ladrillera fue declarado BIC mediante Resolución de 2 de abril de 1996 de la Dirección General de Bienes Culturales (BOJA de 24 de agosto de 1996) y la ciudad romana de Arucci Turobriga y la Ermita de San Mamés fueron inscritas en el Catálogo General del Patrimonio Histórico Andaluz como BIC, con la tipología de Zona Arqueológica la ciudad romana, y con la tipología de Monumento la ermita, mediante el Decreto 407/2008, de 8 de julio (BOJA 152 de 31 de julio de 2008). Existen además, dos inscripciones genéricas colectivas en el CGPHA. Por la Resolución de 7 de mayo de 2003 (BOJA 97 de 23 de mayo de 2003), se inscribieron colectivamente, con carácter genérico, los Dólmenes de la Sierra de Aracena y Picos de Aroche, trece de ellos en el término municipal de Aroche: Monte Perro I, El Torrejón II, La Lamera, Monte Chico, Los Praditos I, Los Puntales, Castellana III, Montero, La Alcalaboza II, La Alcalaboza III, La Portilla, La Corteganesa y La Belleza. Y por último, mediante la Resolución de 28 de julio de 2005 (BOJA 166 de 25 de agosto de 2005), se resolvió inscribir colectivamente, con carácter genérico, treinta y siete yacimientos arqueológicos y poblados amurallados de la Sierra de Aracena y Picos de Aroche, once de ellos del término de Aroche: Las Peñas, Solana del Torrejón, Fuente Seca, Pico de la Muela, Torrequemada, Bejarano, Alto del Naranjo, San Mamés, Los Colorados, Cerro del Cinchato y Valle de la Torre.

A nivel legislativo, por tanto, el patrimonio de la localidad parece estar convenientemente protegido; a pesar de ello, la legislación por sí sola no protege: es necesario usar herramientas de control más cercanas, cuyas competencias deberían recaer en las administraciones locales, para conseguir una protección efectiva, en términos municipales tan amplios como éste $\mathrm{y}$ yacimientos arqueológicos tan poco accesibles.

\section{Conservación}

La conservación es uno de los eslabones más desarrollado durante estos años, con más de 130 intervenciones directas para recuperar y evitar la pérdida de este legado. El Proyecto ha demostrado que una acción tan sencilla como es el mantenimiento y la limpieza diaria de los monumentos y espacios históricos, se convierte en la tarea más importante para su conservación. Podría parecer insignificante, a priori, evitar que crezca hierba, limpiar y cuidar que no existan pérdidas de masa, etc.; sin embargo, esto determinará que una estructura termine por desaparecer o no. En más de una ocasión se ha observado cómo la proliferación de vegetación y la afección que sus raíces ocasionan en las fábricas de determinadas estructuras pueden ser causantes de su pérdida; por tanto, vigilar y mantener el patrimonio es clave para evitar su pérdida o minimizar el coste de futuras restauraciones. El trabajo de mantenimiento se extiende también a las cubiertas de los edificios, tales como la ermita de San Mamés, el Convento de la Cilla o la Iglesia de la Asun- 
ción. Estas limpiezas impiden las filtraciones y consecuentemente sus daños.

La consolidación preventiva de estructuras es otro de los trabajos incluidos en este capítulo. Una adecuada consolidación, con estudio de materiales y la aplicación de morteros específicos, según indicaciones de los especialistas, ayuda a la conservación, evitando la pérdida de masa progresiva mediante la acción de agentes atmosféricos o humanos.

Las obras de restauración y recuperación han sido las más numerosas del Proyecto y las que más han beneficiado al patrimonio y la visión del Conjunto Histórico. El estado en 2003 era realmente alarmante, con la amenaza de derrumbes en algunos de sus principales monumentos y con graves problemas de humedades y filtraciones en otros. Más de dieciséis años de trabajos han permitido la realización de obras muy necesarias, que además han garantizado la entrega del patrimonio al público en general, con aperturas de forma estable y acciones de sensibilización y socialización.

La forma más directa y efectiva de mostrar el cambio generado por el Proyecto en la conservación del patrimonio es acudir al material gráfico. A continuación se esbozan las principales intervenciones acompañadas de imágenes que permiten avalar este trabajo:

1. El Puente de los Pelambres es uno de los pocos ejemplos de arquitectura hidráulica de época de Felipe II en este territorio, y la intervención para su recuperación fue una de las primeras realizadas por el Proyecto, debido a la fuerte simbología de este puente para la población, pero también porque se convertiría en la mejor carta de presentación del Proyecto ante los vecinos y vecinas. También su mal estado de conservación motivaba la elección (Figuras 1 y 2).

2. El castillo de Aroche, de época almohade, ha sido objeto de varias intervenciones, algunas de ellas desarrolladas directamente por la Junta de Andalucía, y otras desde la administración local. Este castillo tiene una curiosa singularidad, y es que su patio de armas fue convertido en coso taurino en 1804, funcionalidad que aún hoy mantiene, aunque se han generado con su restauración otros usos culturales de mayor calado social. A la restauración de los lienzos y torres y la iluminación del monumento (Figura 3), se suma la restauración del graderío de la plaza de toros, la mejora de las instalaciones taurinas, la creación de la Sala del Alcaide (Figuras 4 y 5), la liberación de espacios anexos al castillo (Figura 6) y la creación de espacios ajardinados.

3. La Muralla de Aroche tiene casi 1,2 km de perímetro, y aunque su origen es medieval, su mayor protagonismo estuvo ligado a la Guerra de Restauración Portuguesa durante el siglo XVII. Tras su falta de uso militar, fue dinamitada, usada de muro medianero entre viviendas, horadada hasta provocar su derrumbe, y en general olvidada a su suerte, entendiéndose un estorbo para el crecimiento urbano. En la actualidad se han recuperado ya nueve lienzos (Figura 7), pero además de las obras de restauración (Figuras 8, 9, 10 y 11), se han liberado
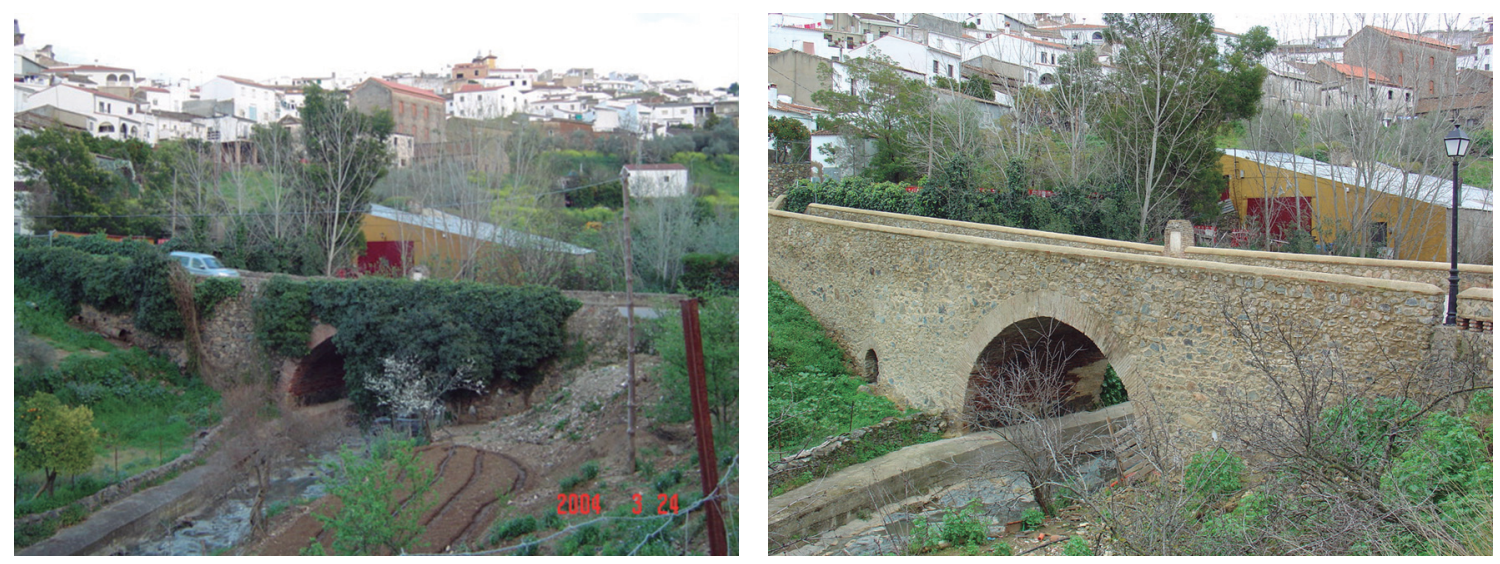

Figuras 1 y 2. Vistas antes y después de la intervención en el Puente de los Pelambres (Fotos: N. Medina). 


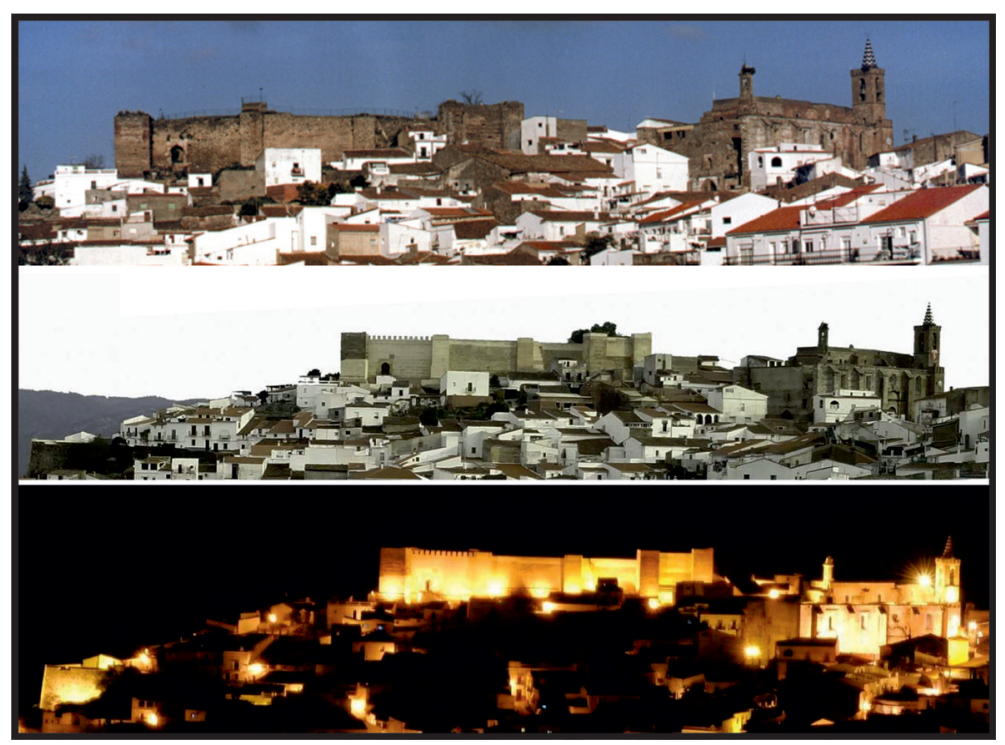

Figura 3. Estado del castillo antes y después de la restauración (Fotos: N. Medina).
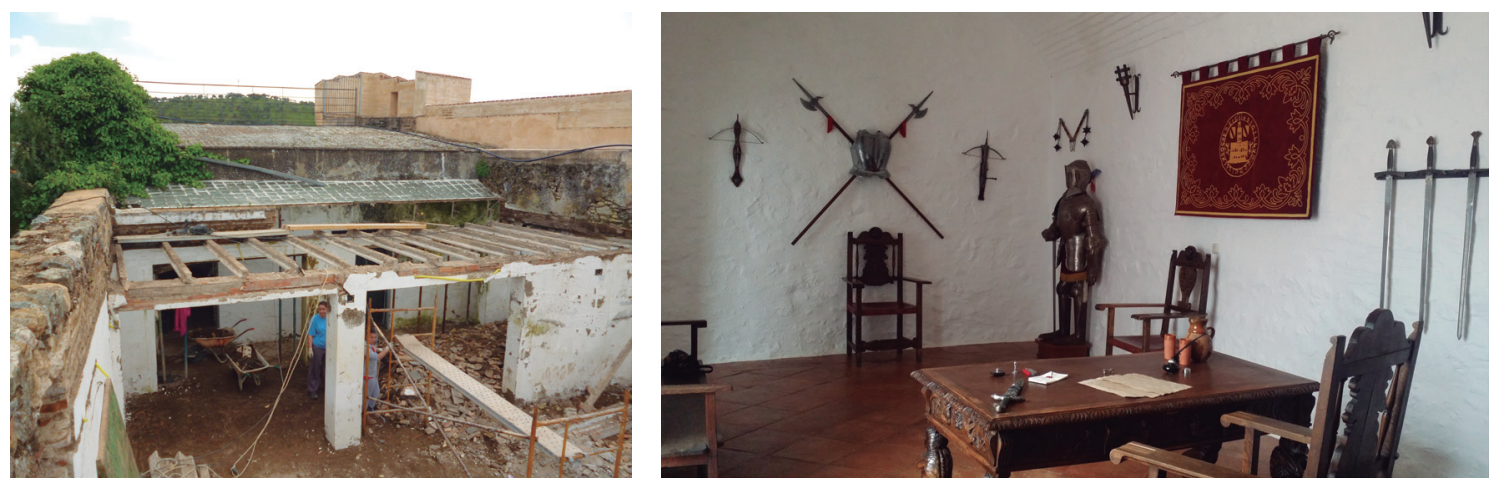

Figuras 4 y 5. Antes y después de la Sala del Alcaide (Fotos: N. Medina).

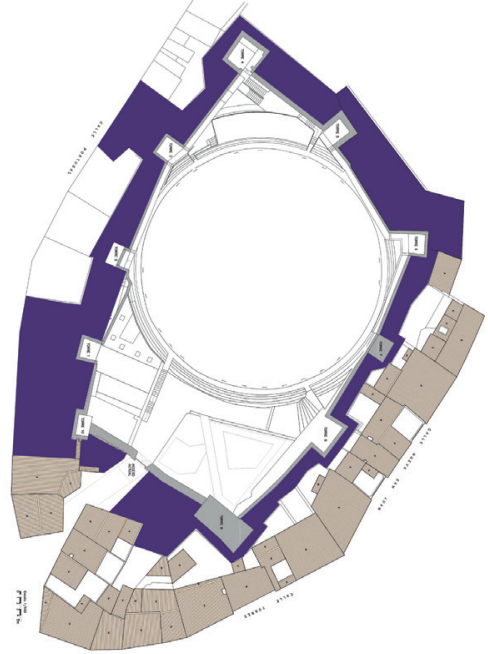

Espacios adquiridos y liberados en el entorno del castillo

Figura 6. Espacios adquiridos y liberados junto al castillo (N. Medina). 


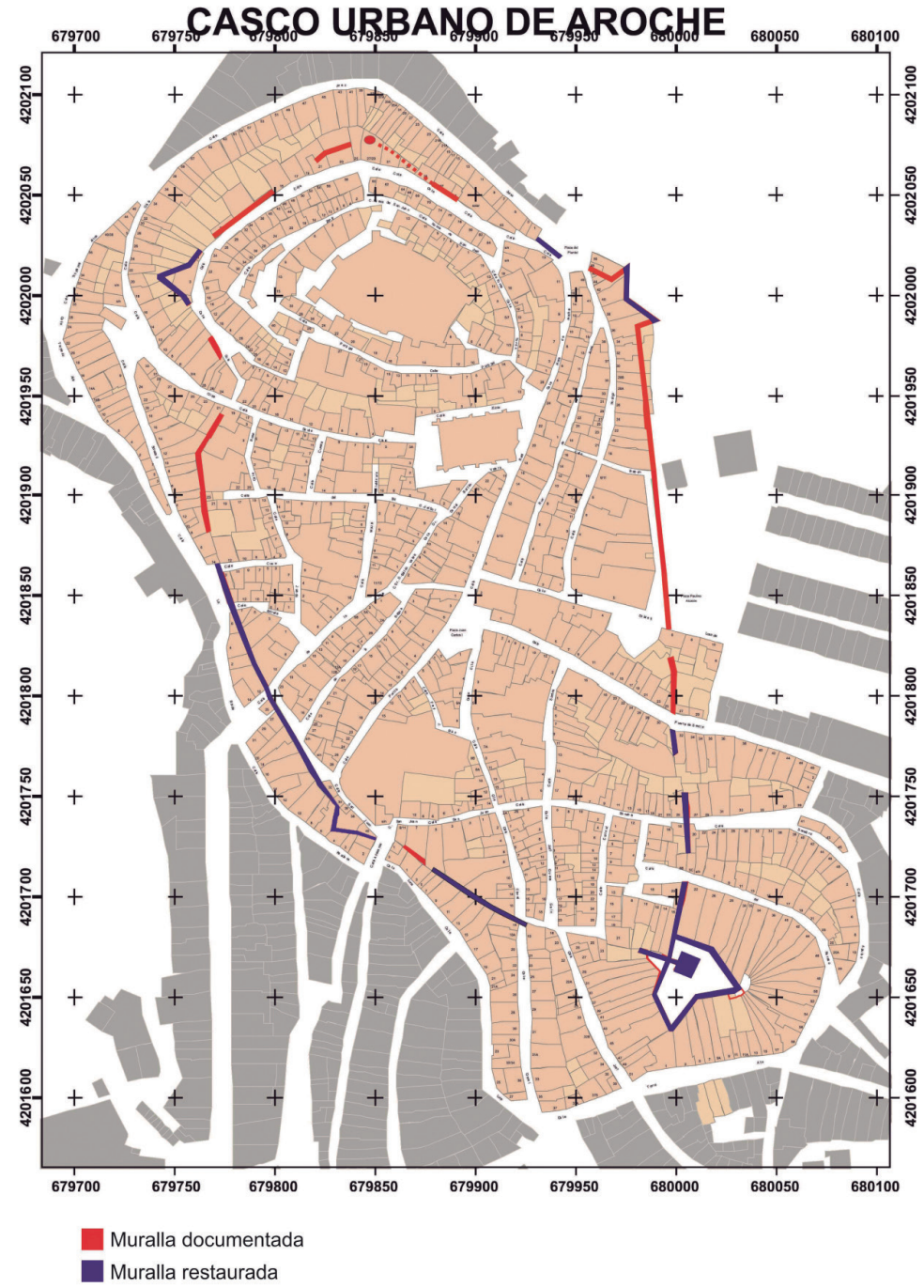

Figura 7. Plano con indicación de los tramos de muralla documentados y los restaurados (N. Medina).
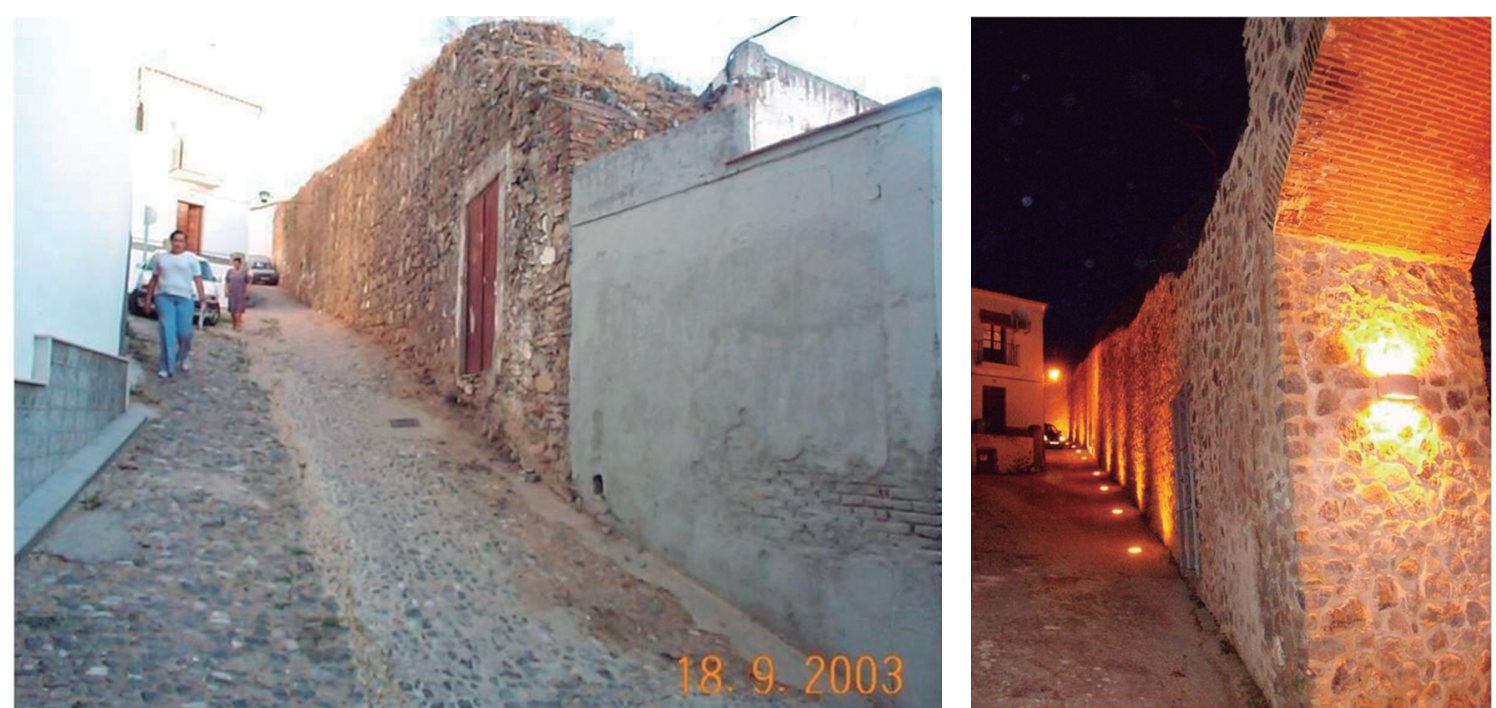

Figura 8. Antes y después del lienzo de muralla en el Callejón del Agua (Fotos: N. Medina). 

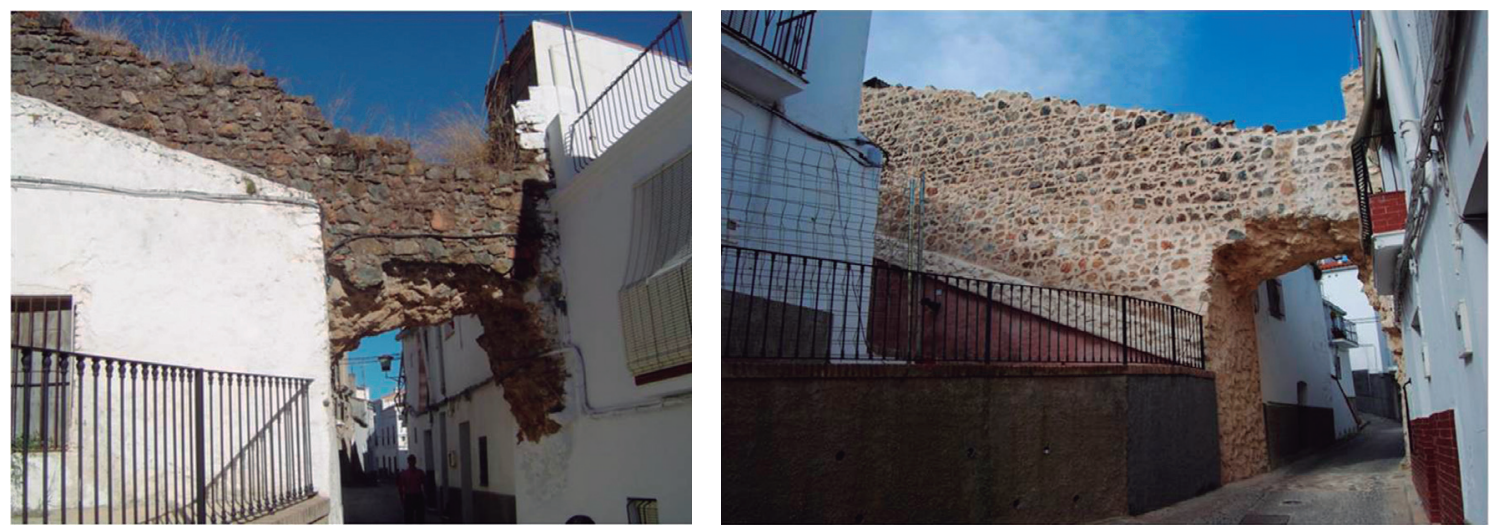

Figura 9. Antes y después del lienzo de muralla en Calle Senabra (Fotos: N. Medina).
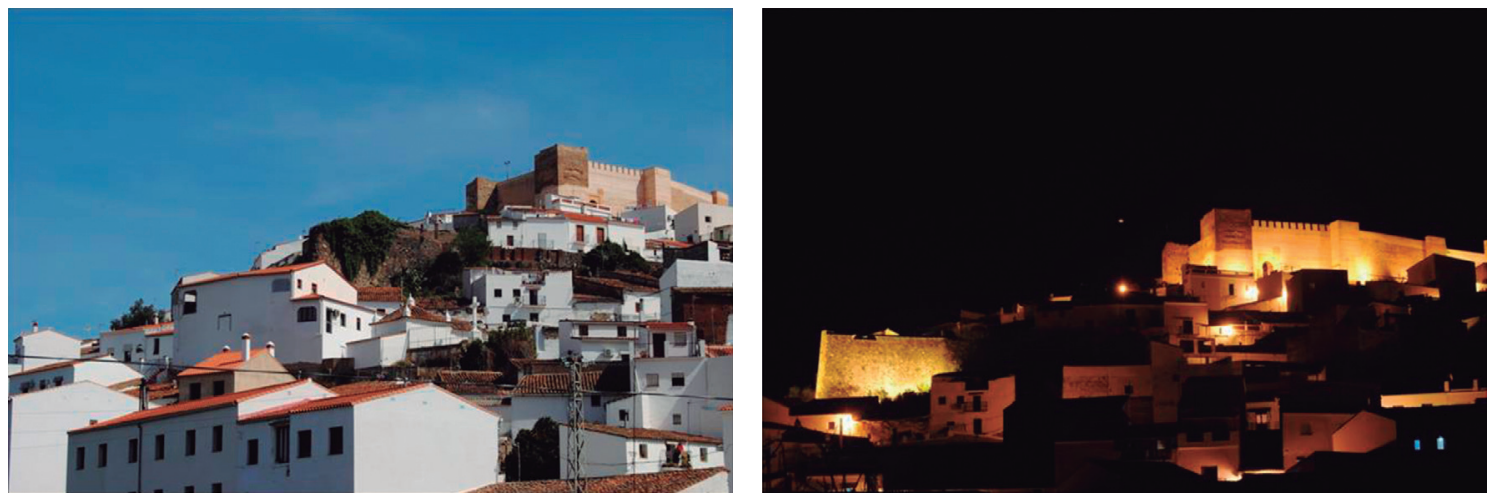

Figura 10. Antes y después del Baluarte de Calle Cota (Fotos: N. Medina).

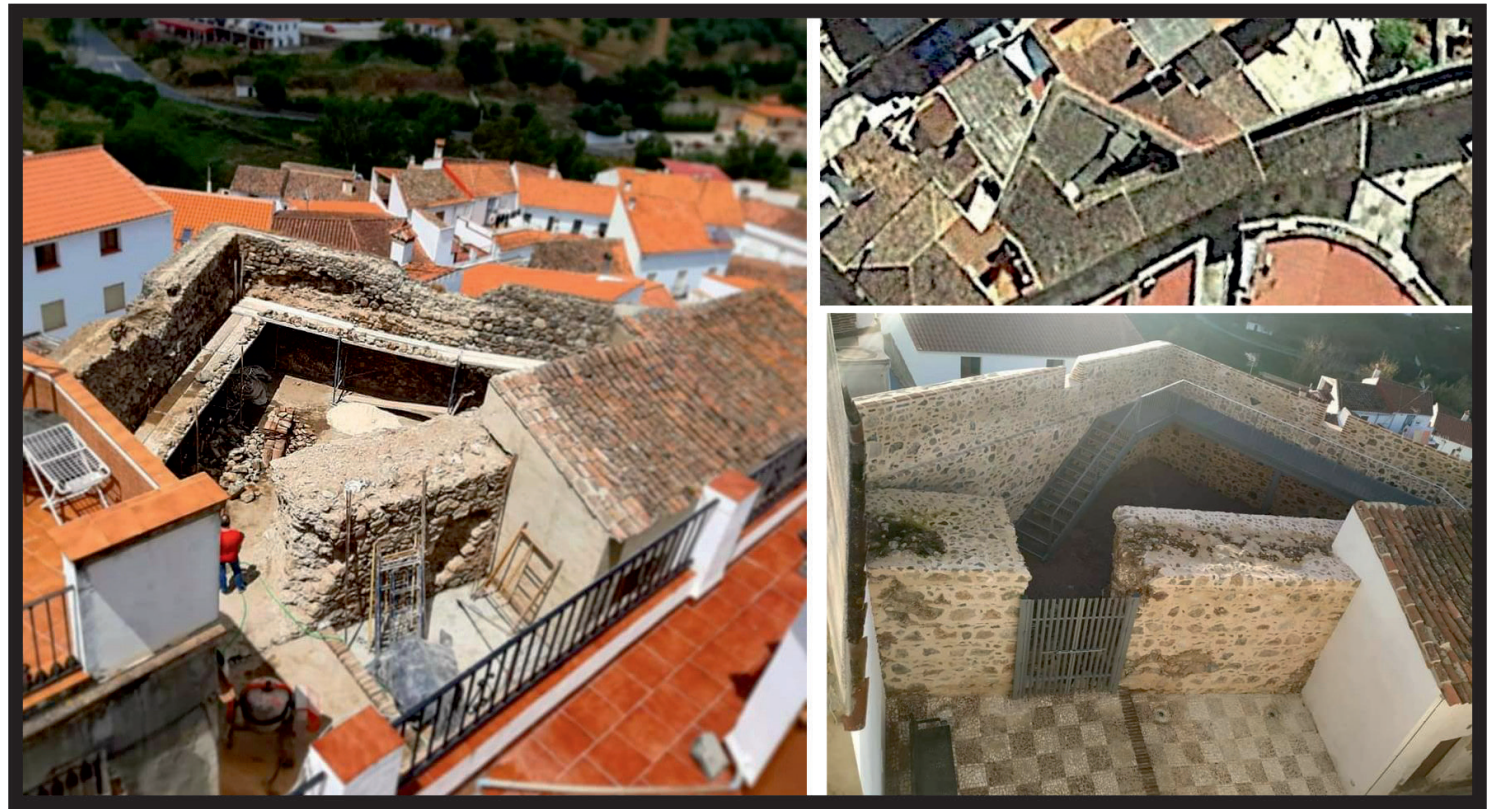

Figura 11. Proceso de recuperación del Baluarte de Calle Portillo (Fotos: N. Medina). 
numerosos espacios colindantes, con la compra negociada de inmuebles abandonados anexos, su posterior derribo y la creación de espacios públicos que permiten las restauraciones, el mantenimiento y la contemplación de esta importante obra militar. Las intervenciones realizadas en la muralla han conseguido no sólo un notable cambio en cuanto a su conservación, sino la recuperación de un símbolo local, muy ligado a la identidad colectiva.

4. La Torre de San Ginés forma parte del sistema defensivo arocheno. Se trata de una torre cuadrangular maciza, de origen medieval, rodeada por una muralla estrellada típica de las construcciones abaluartadas modernas, y lugar donde confluye la muralla perimetral que permitió durante la Guerra de Restauración la protección completa de la Villa. Esta torre, tras su falta de uso, fue progresivamente rodeada por edificaciones que la dejaron inconexa con las calles. Sirvió de cantera de materiales, de espacio para huerto y finalmente de basurero. Tras la adquisición por parte del Ayuntamiento de una de las edificaciones que la rodearon, y su derribo, comenzó un período de más de ocho años de trabajos para su recuperación integral (Figuras 12 y 13).

5. Las intervenciones realizadas en cada uno de los elementos que conforman el patrimonio de la localidad suponen material suficiente para la redacción de varios trabajos. En el caso de la ciudad romana de Arucci, las investigaciones y actuaciones desarrolladas, superan con creces las efectuadas en los demás, y la bibliografía al respecto así lo confirma, aunque debido a la extensión de este trabajo sólo referenciamos algunos de ellos (Bermejo y Campos 2009; 2011; 2013; Medina 2013; etc.).

Ante la situación de abandono de este importante yacimiento, el primer paso consistió en la limpieza y adecuación de las zonas excavadas en los años 90 del pasado siglo (Figura 14). Una vez recuperados esos espacios, se realizaron más de veinte intervenciones arqueológicas, amparados en tres Proyectos Generales de Investigación, algunas intervenciones puntuales, además de otras tantas intervenciones de consolidación y adecuación de espacios para integrarlos en un circuito de visitas (Figura 15), garantizándose en todo momento la conservación de los restos, pero también el disfrute de los mismos por parte de la sociedad. Se han documentado (hasta la actualidad) el foro, las termas, el macellum, el campus, la necrópolis norte, y tres ambientes domésticos: la Casa de la Columna, la Casa del Peristilo y la Casa Norte, además de parte del viario vinculado a estos edificios. El yacimiento ha alcanzado un elevado nivel de investigación, que lo ha posicionado científicamente a nivel nacional e internacional.

6. En la medieval ermita de San Mamés, asentada sobre los restos de la Basílica de Arucci, se han realizado numerosas intervenciones, siendo la más importante la restauración de sus importantes frescos de los siglos XIV-XVII (Figuras 16 y 17). También se ha intervenido en sus cubiertas y en la adecuación de sus espacios aledaños, con el soterramiento
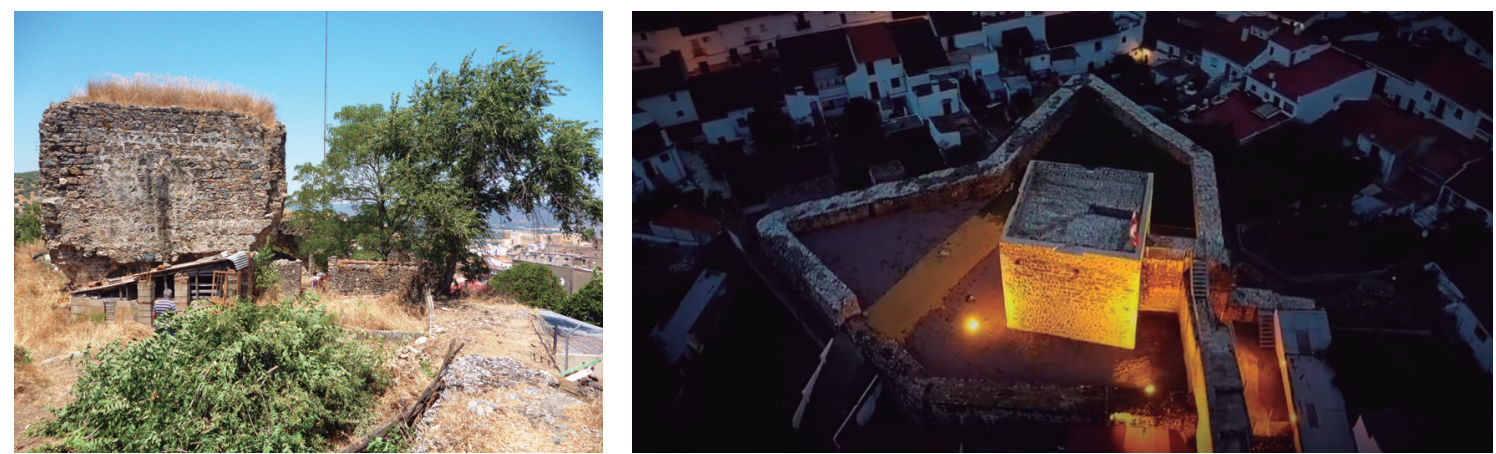

Figuras 12 y 13. Antes y después de la recuperación de la Torre de San Ginés (Fotos: N. Medina y J. Fernández). 

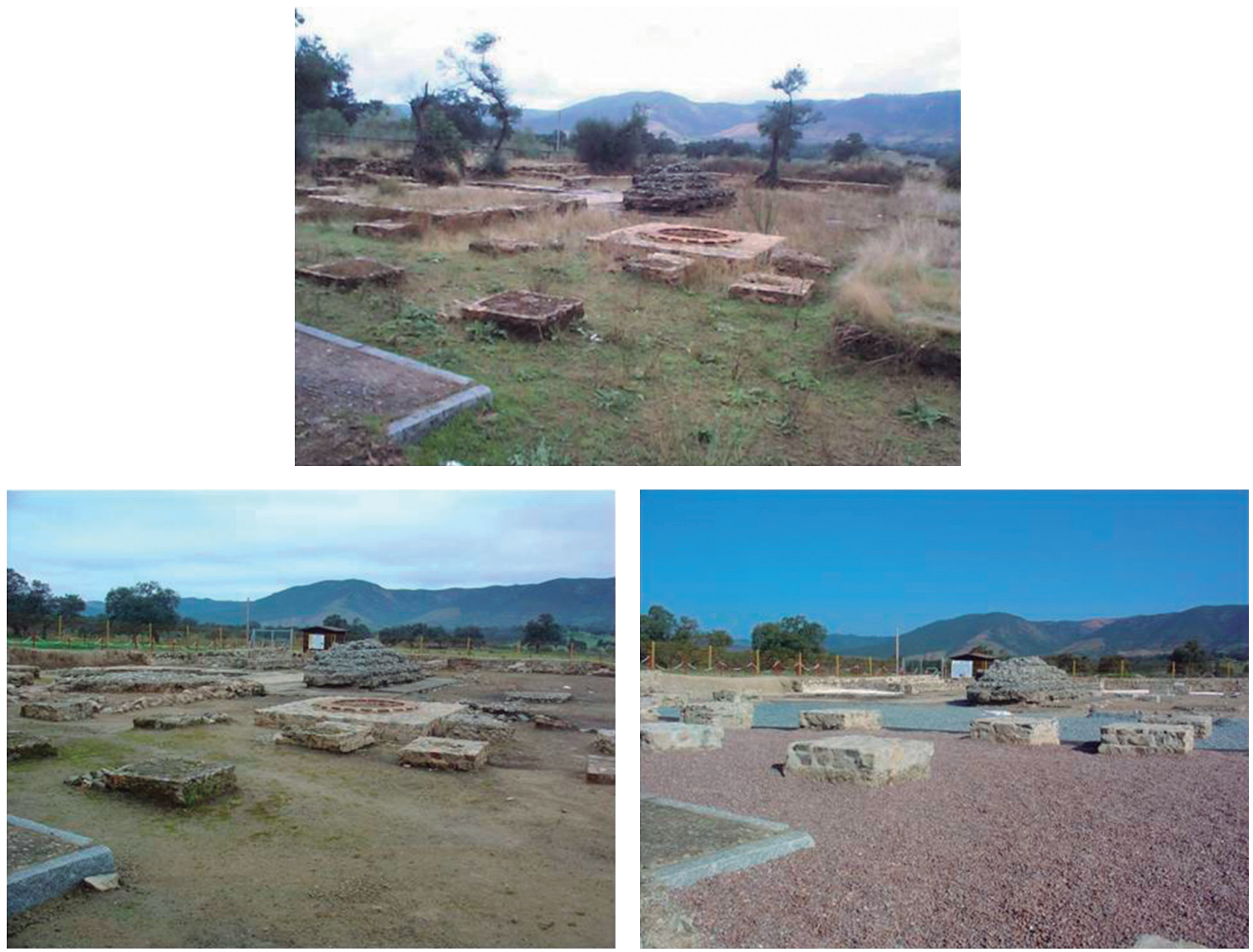

Figura 14. Recuperación de espacios excavados de Arucci Turobriga (Foto: N. Medina).

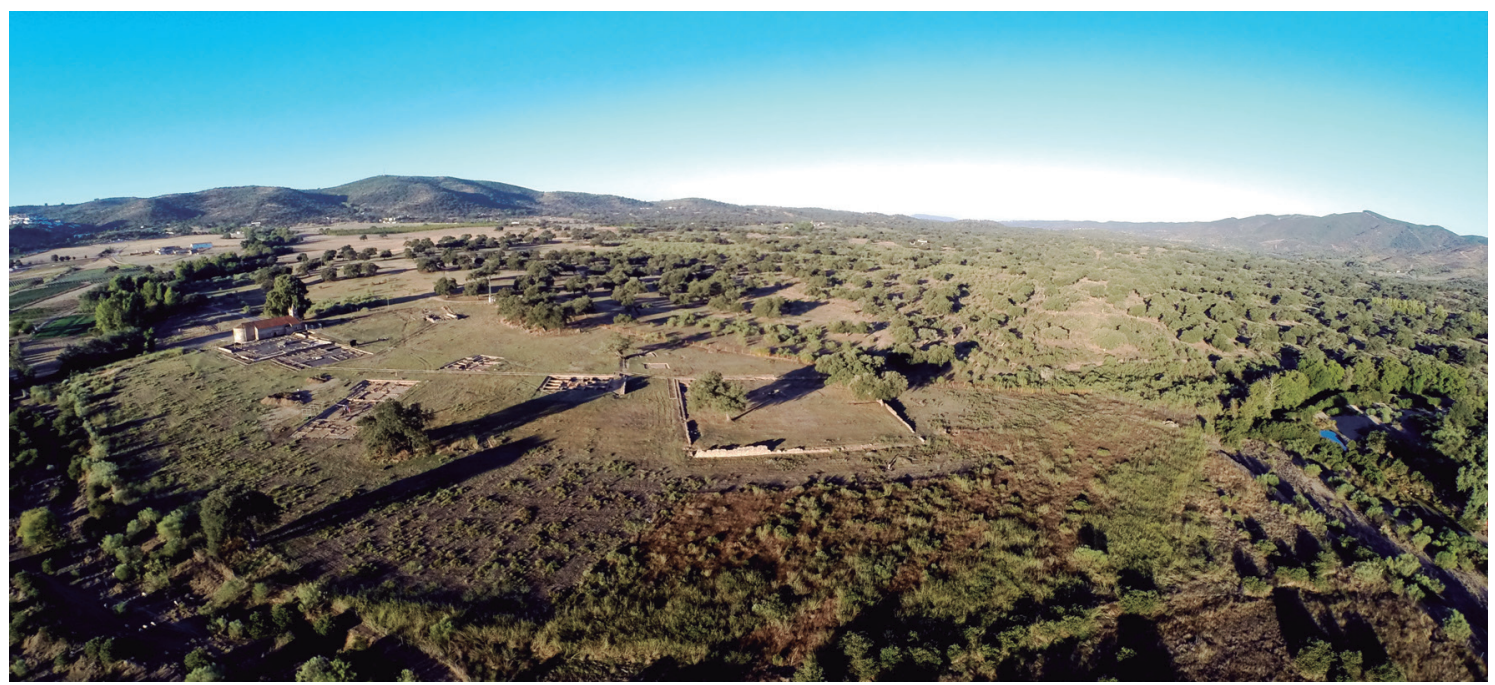

Figura 15. Vista aérea actual de Arucci Turobriga (Foto: Grupo Vrbanitas, Universidad de Huelva).

del cableado aéreo, la creación de una zona de aparcamientos, parque infantil, aseos públicos y mejora de accesos.

7. El Convento de la Cilla, del siglo XVII, ha sido objeto de mejoras en las cubier- tas, reparación de humedades y de un chapitel dañado por un rayo. En su interior se han creado dos nuevas salas de exposición (Figura 18), que se suman a las cuatro existentes. El Convento alber- 

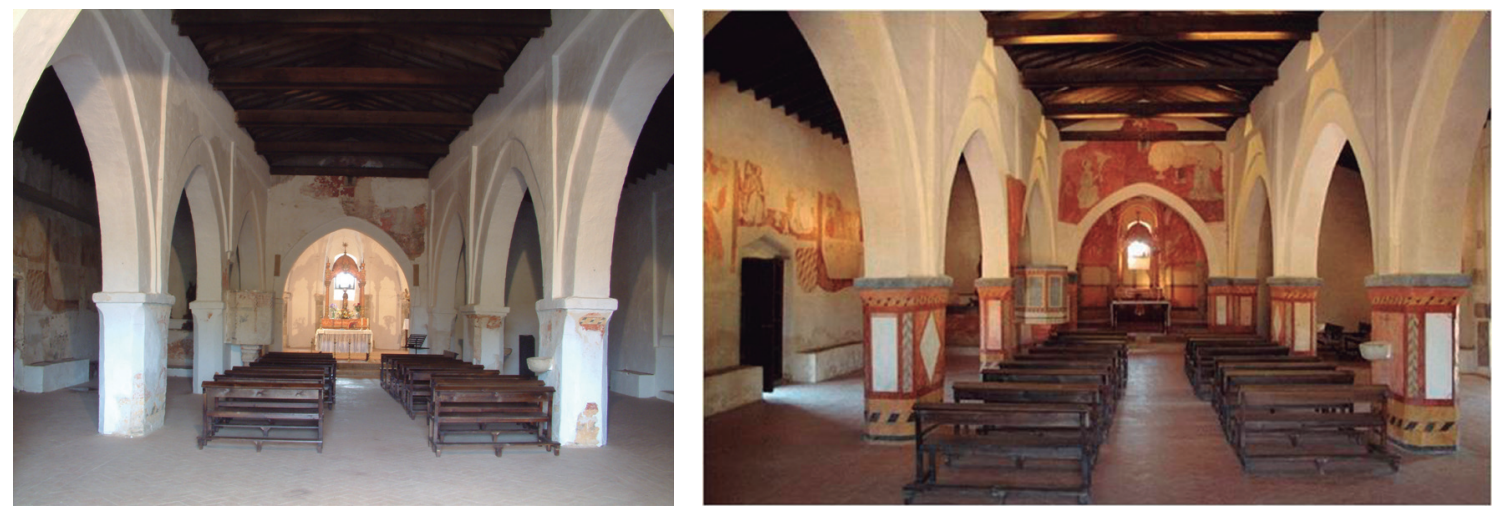

Figuras 16 y 17. Estado de la ermita de San Mamés antes y después de la intervención (Fotos: N. Medina).
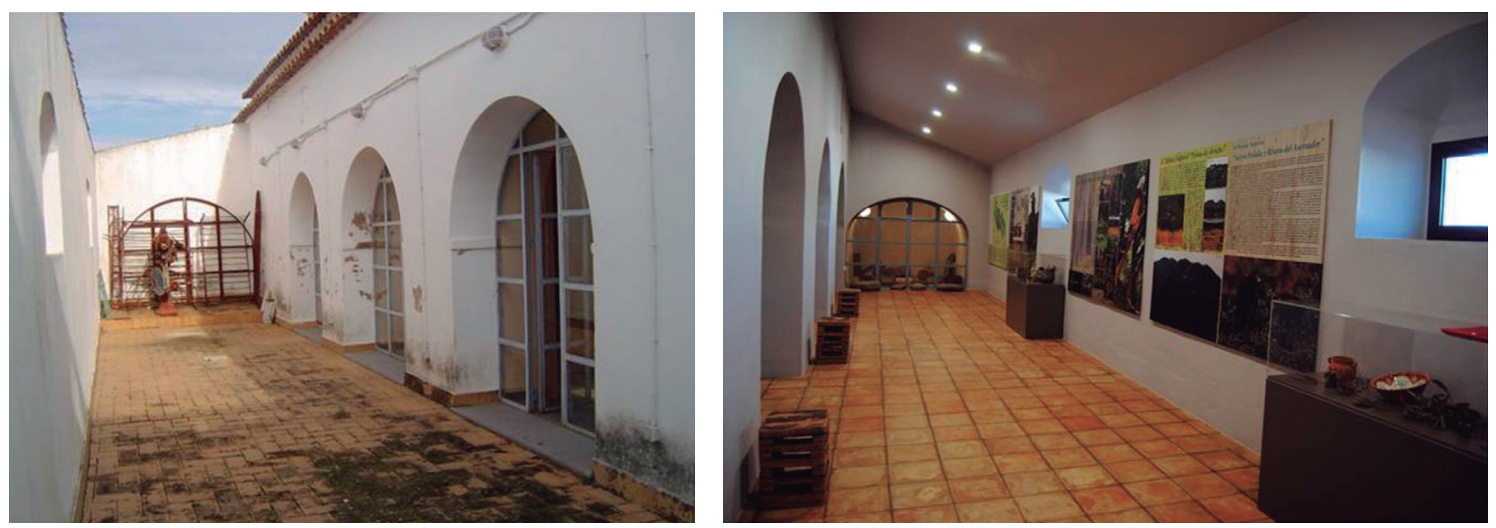

Figura 18. Patio del convento convertido en nueva sala de exposición (Fotos: N. Medina).

ga el Centro de Recepción de Visitantes, la Colección Arqueológica Municipal, el Museo del Rosario y un Punto de Información del Parque Natural Sierra de Aracena y Picos de Aroche.

8. La Iglesia de la Asunción es un templo mandado a construir a finales del siglo XV por los Reyes Católicos, posiblemente sobre los restos de una antigua mezquita. Han sido históricos los problemas de humedades y filtraciones de agua, que obligaron en varias ocasiones al techado de las bóvedas, proyectadas como bóvedas vistas (Medina, González y Acedo, e.p.). A lo largo de estos años han sido varias las intervenciones realizadas para mantener y conservar este edificio (Figura 19), que sin ser propiedad municipal, el consistorio parece obligado. A cambio, tras un acuerdo con la parroquia, el Ayuntamiento puede hacer uso turístico y cultural del templo.
9. Aroche ha sido tratado como un yacimiento único, y el Conjunto Histórico ha sido objeto de infinidad de obras para su mejora y conservación. Estas obras han incluido la renovación de pavimentos empedrados tradicionales, la creación y mejora de espacios públicos, zonas ajardinadas, la eliminación de cableado aéreo, etc., promoviendo incluso la ayuda a los vecinos y vecinas en cuanto a la conservación de restos arqueológicos o arquitectónicos de interés aparecidos en las obras de sus viviendas (Figuras $20 \mathrm{y}$ 21). Y es que el patrimonio no debe percibirse como una carga, sino como algo propio, donde todos deben contribuir a su protección.

10. Por último, podemos citar actuaciones en diferentes edificios y espacios arqueológicos, como en el yacimiento califal de la Ladrillera, en un horno artesanal de fabricación de ladrillos, en el Puente de Santa María, en el Puente 


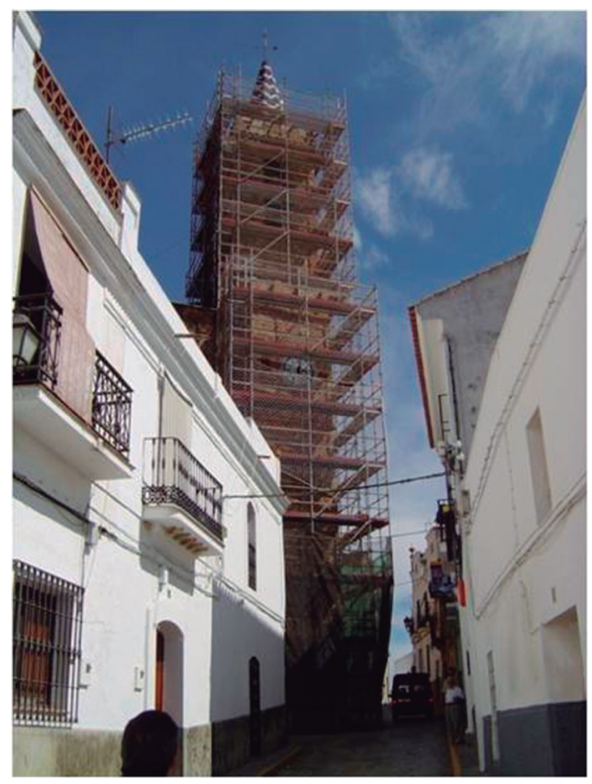

Figura 19. Vistas del proceso de obras en la Iglesia de la Asunción (Foto: N. Medina).
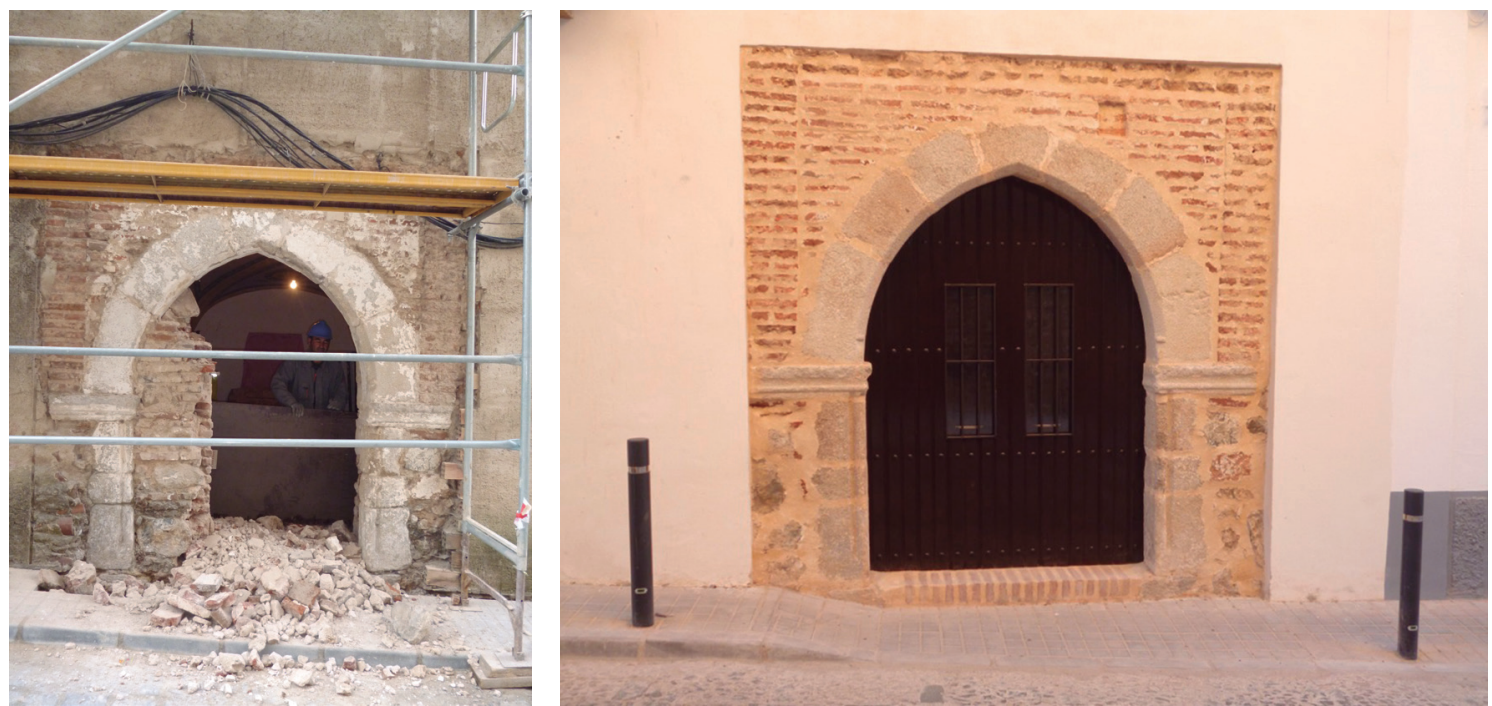

Figuras 20 y 21. Recuperación de una portada medieval en una fachada privada (Fotos: N. Medina).
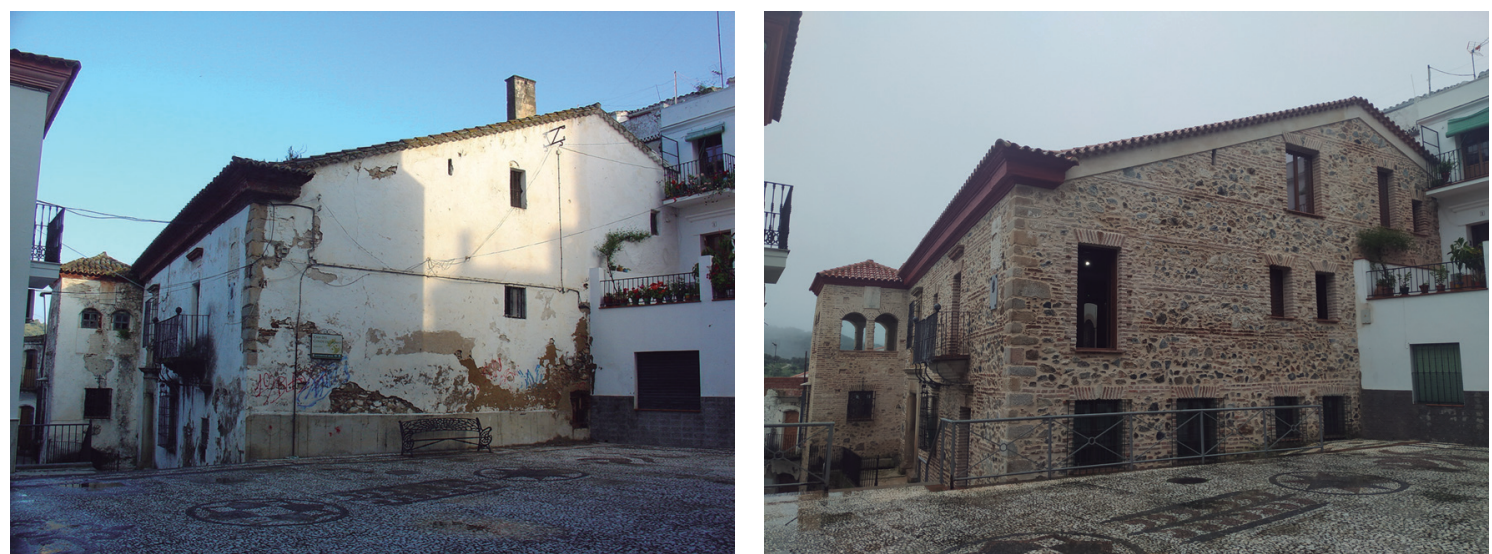

Figuras 22 y 23. Antes y después de las obras en la Casa Palacio Conde del Álamo (Fotos: N. Medina). 
de la Villa, etc. Quizás una de las obras más significativas está siendo la restauración de la Casa Palacio del Conde del Álamo, del siglo XVIII, para su uso como hotel con encanto. Un edificio privado cuyas obras se abandonaron con la crisis inmobiliaria de 2008, y que el Ayuntamiento decidió adquirir y restaurar a fin de dotar al municipio de un equipamiento muy necesario teniendo en cuenta el aumento progresivo que ha experimentado el turismo (Figuras 22 y 23).

\section{Socialización}

El concepto de socialización es relativamente nuevo; una evolución del trabajo de difusión aplicado al patrimonio, y muy en relación con el desarrollo del concepto de gestión del patrimonio que ha tenido que inventar mecanismos de comunicación, interpretación y acercamiento, sirviendo de mediador entre la sociedad y su pasado tendiendo puentes en donde ambos han podido reconocerse (Pérez-Juez 2010). La Socialización se relaciona con lo que tendía a denominarse Difusión, como un vínculo entre el Patrimonio y la Sociedad (Martín 2007), pero ahora trasciende ese término, e incluye la difusión científica del patrimonio, la difusión y promoción turística, la participación ciudadana, la conversión del patrimonio en un recurso y equipamiento cultural, un producto turístico y un recurso educativo (Delgado y Jaén 2016). En este sentido el modelo de Aroche ha conseguido una difusión científica gracias a la colaboración del Grupo Vrbanitas de la Universidad de Huelva, sobre todo en lo que al yacimiento arqueológico de Arucci Turobriga se refiere; una difusión turístico-cultural a través de redes sociales y con empresas especializadas del sector, la participación en ferias de turismo, la creación de productos turísticos, etc., así como un acercamiento del patrimonio a los centros educativos con visitas guiadas, participación en intervenciones arqueológicas, campañas de sensibilización, participación ciudadana, etc.

Los principales espacios histórico-arqueológicos cuentan con apertura estable al público, y una programación anual que acerca el patrimonio a la sociedad local y también a los visitantes, cada vez más numerosos. La socialización también es entendida como una democratización del patrimonio y el conocimiento, llegando a todo el público, con el uso de herramientas y metodologías que permitan ese acercamiento sin perder rigor histórico. Se han creado una serie de eventos vinculados al patrimonio, concebidos como una forma de volver a dar vida a los espacios y monumentos (Medina e.p.b), sin poner en riesgo la conservación de los mismos. El Castillo acoge en verano La Noche de las Velas, con música y recreación histórica a la luz de miles de velas; la Torre de San Ginés, incluso durante el proceso de restauración, ya servía de escenario a las Noches de la Almena, con teatro flamenco; los patios del Convento de la Cilla son el escenario del Festival de la Cilla, con actuaciones musicales; el Paseo de la Iglesia es un espacio idóneo para el Certamen de Bandas de Música; y en el yacimiento de Arucci se celebra el Festival de Diana, una festividad de origen romano dedicada a la diosa de la caza y la naturaleza, presente en el templo del foro de $\mathrm{Arucci}$, y que conjuga recreacionismo histórico, teatro clásico, visitas guiadas, talleres, degustaciones, desfiles, etc. (Medina e.p.b) (Figuras 24 y 25)

Estos eventos han generado una enorme repercusión social, cultural y también turística, pero lo más destacable es que a nivel local han conseguido fortalecer las señas de identidad colectiva, la relación de los vecinos con el territorio y la apropiación de la historia y el patrimonio por parte de la sociedad local, a través de una participación activa. El patrimonio genera un sentimiento positivo de identidad territorial que incide en el bienestar individual (Rausell 2014). El Festival de Diana en concreto ha logrado la creación del Grupo Municipal de Recreación Histórica Baebia Aruccitana, con una sección civil, otra militar, y una novedosa sección musical, vinculada al Aula Municipal de Música. Este grupo cuenta con más de un centenar de participantes de edades entre los 5 y los 75 años.

Se ha fomentado la colaboración territorial, con la presentación de proyectos conjuntos entre municipios de la Comarca, como por ejemplo un pasaporte turístico, que incluye los municipios de Aracena, Almonaster, Alájar, Cortegana y Aroche. Y la colaboración transfronteriza, con la creación de la Ruta del Territorio Hospitalario y el Festival del Territorio Hospitalario, que une a los municipios de Aracena y Aroche por la parte española y Serpa y Moura por el lado portugués, todos con un pa- 


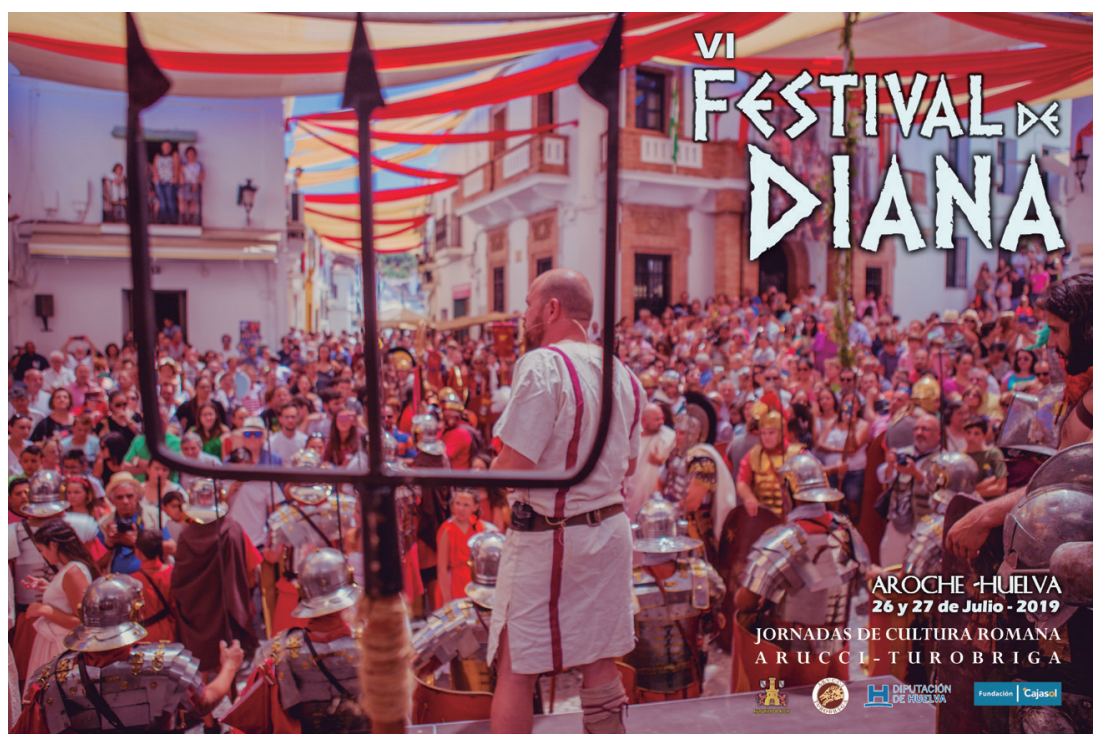

Figura 24. Cartel de VI Festival de Diana (Ayuntamiento de Aroche).

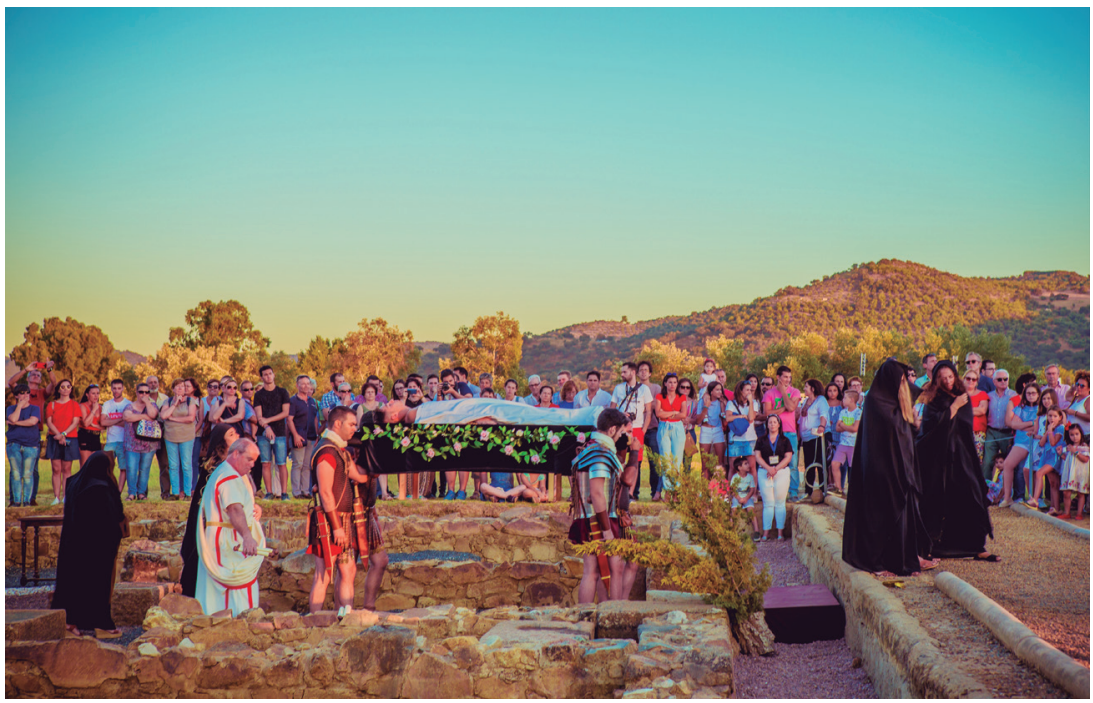

Figura 25. Recreación histórica en el Festival de Diana (Foto: T. Palluch).

sado medieval ligado a la Orden del Hospital de San Juan.

El recreacionismo histórico se ha convertido en una eficaz herramienta de socialización del patrimonio (Figura 26), que requiere imprescindiblemente de la investigación (Vaquerizo 2018), porque es ese conocimiento el que garantiza el rigor histórico y la veracidad, evitando el efecto de decorado cinematográfico (Moreno y Sariego 2017). Las recreaciones históricas han experimentado un gran auge en los últimos años, y se han convertido en una herramienta indispensable para la gestión (Pérez-Juez 2010). No debemos identificar la socialización del patrimonio con la prolifera- ción de fiestas temáticas que usan el patrimonio como pretexto y no como contexto. Este tipo de herramientas están entroncadas con el desarrollo de la arqueología pública o más bien comunitaria (Almansa 2011; Ayán 2014), con el objetivo de implicar a la sociedad local en el proyecto. Y es que sólo partiendo de una información histórica bien documentada se puede recrear científicamente el pasado (Moreno y Sariego 2017). En opinión de Vaquerizo (2018), la difusión bien entendida, además de completar el ciclo natural y obligado del trabajo arqueológico, representa un yacimiento formidable de empleo no sólo para los arqueólogos, sino también para otros colectivos 


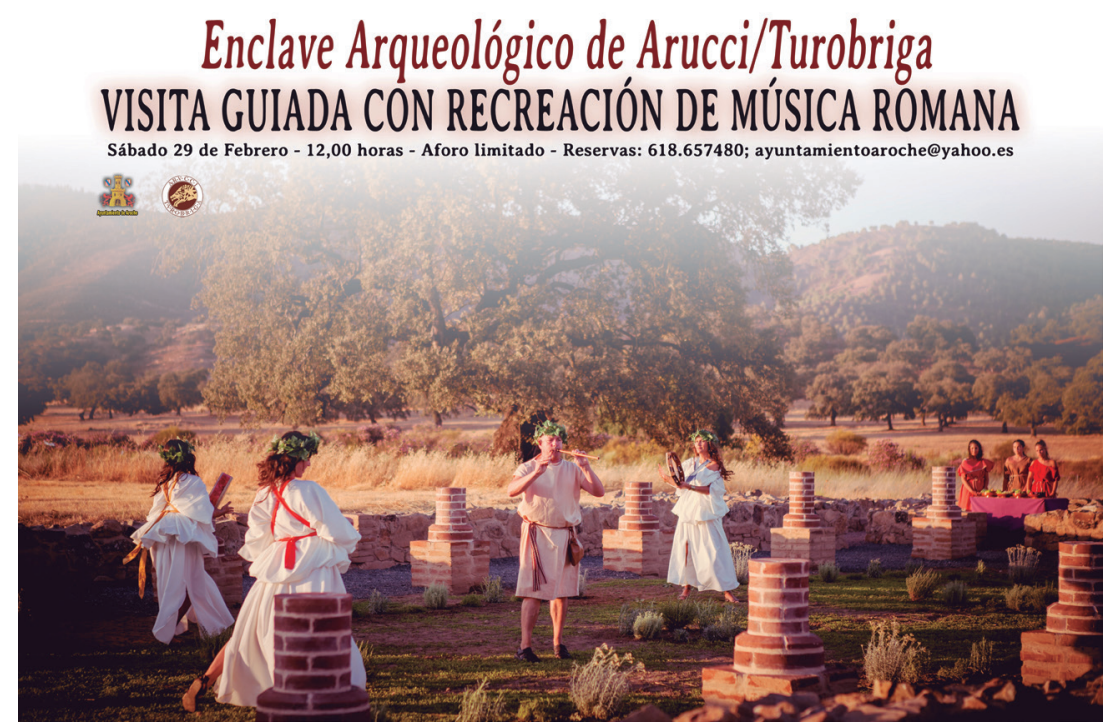

Figura 26. Cartel recreación histórica de música romana en la Casa del Peristilo de Arucci (Ayuntamiento de Aroche).

relacionados con el patrimonio, el turismo, la cultura, la hostelería, el arte...

\section{Financiación del proyecto}

En muchas ocasiones sucede que la consecución de grandes subvenciones no representa una garantía para la conservación del patrimonio. Pueden verse grandes carteles anunciadores de inversiones (fondos europeos principalmente), junto a yacimientos y centros de interpretación cerrados y abandonados. Aquí no ha habido grandes inversiones. Ha sido un proyecto humilde en cuanto a su financiación, con pequeñas pero constantes aportaciones, sobre todo de carácter municipal, que han permitido la creación de empleo estable vinculado a la gestión (dirección, obras, mantenimiento y difusión turística), y abundante empleo temporal (obras, mantenimiento, eventos, etc.). Las actuaciones más importantes y con carácter anual han sido acometidas generalmente con fondos del Plan de Fomento de Empleo Agrario (PFEA), ese fondo tan denostado desde algunos sectores fuera de Andalucía, pero tan necesario aquí, como en otros lugares lo son las ayudas a otros sectores económicos, como el automóvil por ejemplo. Este programa, financiado a través del Gobierno de España, la Junta de Andalucía y la Diputación Provincial, supone una inversión cercana al millón de euros anuales para Aroche. Gran parte de esta inversión se emplea para actuaciones enmar- cadas en el Proyecto Patrimonio, y son estos fondos los que han permitido un desarrollo equilibrado de este plan, con un alto nivel de ejecución y con una gran repercusión social, cultural y económica.

Otras financiaciones llegaron a través de los fondos europeos (líneas FEDER e INTERREG principalmente), ayudas de la Junta de Andalucía y de la Diputación Provincial de Huelva, además de la colaboración de la Universidad de Huelva, Fundación Cajasol, o incluso, un mecenas local, Atlantic Blue S.L.

\section{Logros del proyecto}

No dudamos en afirmar que se han cosechado logros significativos y Aroche se ha convertido en un ejemplo de buenas prácticas. Estos logros, a nivel local, se han traducido en la recuperación de buena parte de un patrimonio que estaba anclado en el olvido y al borde de su desaparición en alguno de los casos. La generación de empleo, es otro de los beneficios, con la creación de puestos de trabajo, indefinidos algunos y temporales otros. El tercer logro lo encontramos en el aumento considerable del turismo.

La consecución del Premio Sísifo del Patrimonio en 2018, entregado por la Universidad de Córdoba, el Grupo de Investigación Sísifo y la Asociación Arqueología Somos Todos, fue uno de los reconocimientos más importantes a los logros del proyecto. 
En investigación y conocimiento, ya se ha mencionado la generación de una amplia bibliografía, donde la inestimable colaboración de la Universidad de Huelva ha resultado crucial. El primer objetivo era conocer el patrimonio, pues sin su consecución no podríamos llegar al último, entregar el patrimonio a la sociedad.

Respecto a la protección, la incorporación de los datos de la Carta Arqueológica al PGOU, así como un mayor control de las obras con la creación de la Oficina Municipal de Urbanismo y Patrimonio han supuesto un notable éxito.

En cuanto a la conservación, el mantenimiento periódico de los monumentos y espacios históricos-arqueológicos con personal específico para tales fines y con una dirección técnica y una decisión política fuerte, han supuesto un significativo cambio, no sólo en lo que al estado actual de conservación se refiere sino también en la necesidad de obras de restauración futuras.

A nivel social, se ha enseñado de alguna forma a los ciudadanos a amar su patrimonio, a hacerles sentir orgullosos de su pasado, reforzando sus señas de identidad colectiva, haciéndoles partícipes de su recuperación y sobre todo permitiéndoles disfrutarlo. El nuevo uso de los monumentos ha sido fundamental en este proceso de cambio, pero también, la generación de empleo y el aumento del turismo. Gran parte de la población ha participado en las tareas de excavación, restauración o actividades relacionadas con el patrimonio en los últimos diecisiete años. La mayoría de estos trabajadores lo han hecho en contratos temporales, convertidos en un importante complemento a la economía familiar. Algunos trabajadores incluso han conseguido un contrato estable La población se ha visto beneficiada con la creación de nuevos eventos, que además han generado más turismo, más cultura y más economía.

Por último, otros logros del proyecto, los encontramos en el Instituto de Enseñanza Secundaria de Aroche que lleva el nombre de Turobriga; la Asociación de Mayores se denomina "Arucci Vetus"; varias calles del municipio llevan el nombre de edificios excavados en la ciudad romana como "Calle Campo de Marte", "Calle de las Termas", "Calle de la Casa Norte" o "Plaza del Foro"; se ha creado el Grupo de Recreación Histórica Baebia Aruccitana; una asignatura del Aula Municipal de Música es sobre "Música, Danza y Cultura romana"; y se han exportado a Centroeuropa arándanos de Aroche con el nombre de "Arucci Berris". En general podemos decir que se está produciendo una apropiación ciudadana del patrimonio, necesaria para garantizar la conservación y el futuro de este legado.

\section{Conclusiones}

Desde marzo de 2019 a la actualidad todos los proyectos han tenido que reescribirse, pero las consecuencias generadas por la pandemia del Covid-19, pueden de alguna forma convertirse en una oportunidad de futuro. El redescubrimiento de los pueblos por parte de la sociedad urbana invita a desarrollar nuevas líneas de trabajo, en un momento socioeconómico de gran complejidad y variabilidad, pero donde el turismo de interior parece haberse afianzado, convirtiéndose en una oportunidad real de desarrollo. Las administraciones públicas deben crear herramientas que permitan una mayor participación ciudadana que favorezca la organización de una red de trabajo, colaboración y aportación social, que garanticen un desarrollo social, cultural, y económico sostenible. La pandemia ha puesto de manifiesto las debilidades de la economía española y consecuentemente la necesidad de una transformación estructural y una mayor digitalización. Los fondos europeos Next Generation deben impulsar este proceso de transformación y desarrollo más sostenible desde el punto de vista económico, social, territorial y medioambiental.

Y si la realidad socioeconómica es compleja y cambiante, también podemos decir lo mismo de la Arqueología. En los últimos tiempos se ha convertido en una disciplina que evoluciona constantemente, pasando de estar vinculada exclusivamente al mundo academicista a integrarse en la sociedad. La Arqueología ya no sólo genera conocimiento científico, sino que ahora lo divulga socialmente, generando al mismo tiempo empleo, cultura, economía, sensibilización hacia el patrimonio, protección y conservación. La visión y el concepto de patrimonio también ha evolucionando, pasando de ser objeto de contemplación y estudio, a jugar un papel destacado en su contexto territorial y social. Vinculada a esta evolución de la disciplina arqueológica y de la visión del patrimonio, la gestión ha ido ocupando cada vez más un lugar indispensable en relación al 
patrimonio y al desarrollo social, cultural y económico. La gestión integral del patrimonio debe aunar de forma equilibrada las responsabilidades políticas, institucionales, profesionales y sociales (Delgado y Jaén 2017) y no debe estar reñida con la rentabilización económica, cultural y social.

Desde los ámbitos academicistas se ha cuestionado recurrentemente el aprovechamiento del patrimonio, dando a entender que las administraciones lo usaban para su enriquecimiento, o generando una idea despiadada del productivismo y el crecimiento económico vinculado a estos recursos. El pasado puede permitir el empoderamiento de poblaciones con escasos recursos económicos, y lejos de la visión negativa que tilda de mercantilismo la relación entre patrimonio y turismo, se presenta como una herramienta de desarrollo de comunidades, en este caso, rurales, cuya supervivencia se ve cada día más amenazada por la despoblación. La gestión del patrimonio es un campo en constante evolución, con experiencias cada vez más numerosas, impulsadas por el incremento considerable del número de usuarios o consumidores de patrimonio, que igualmente ha provocado un auge del turismo cultural y arqueológico (Pérez-Juez 2017). Al margen de estas cuestiones queremos pensar que estos cambios también son consecuencia de una mayor responsabilidad de los gobernantes, o de la sociedad en general, por mantener y legar a las generaciones futuras parte de nuestra Historia.

El aumento del turismo cultural también está en relación con las nuevas formas de difusión y acercamiento al patrimonio. La incorporación de las nuevas tecnologías tanto en la aplicación directa, como los nuevos canales o vías de difusión más populares como las redes sociales, los blogs especializados o las guías y plataformas digitales han permitido una cierta democratización del patrimonio. Esta tendencia se ha materializado también en el creciente interés de las administraciones en esta materia, o la proliferación de cursos, másteres o congresos (Ruiz Zapatero 2017), impulsando la aparición de un cada vez más numeroso volumen de manuales sobre el patrimonio y su gestión (Ballart 1997; Querol y Martínez 1996; Ballart y Tresseras 2001; Pérez-Juez 2006; Querol 2010; García Cuetos 2012). Se define la gestión del patrimonio arqueológico como el conjunto de actuaciones destinadas a hacer efectivo su conocimiento, su conservación y difusión, que incluye ordenar y facilitar las intervenciones que en él se realicen (Querol y Martínez 1996: 25). Tanto el concepto de gestión del patrimonio como la profesión han ido definiéndose a medida que han ido practicándose (Pérez-Juez 2010).

El modelo de Aroche concibe la gestión como algo integral, que incluye actividades de planificación, promoción y difusión, pero también de intervención, de restauración, de excavación, de investigación, de mantenimiento, de protección, etc. Se define por tanto como una gestión integrada, que afecta a todas las facetas del patrimonio y cuyo objetivo último es conocer el bien, protegerlo, conservarlo y entregarlo a la sociedad. La gestión, por supuesto, define y planifica dónde, cómo, cuándo y con qué fondos actuar. Y en este momento coyuntural, un proyecto de gestión se presenta como una oportunidad de futuro, sobre todo desarrollada desde el ámbito municipal. Es desde estas administraciones locales desde donde deben elevarse propuestas encaminadas al desarrollo rural vinculado al patrimonio y al reto demográfico, favoreciendo la diversificación económica y el desarrollo sostenible. Así mismo, impulsando foros de debate donde exponer modelos prácticos en los que el patrimonio se convierta en eje de la dinamización económica de comarcas rurales con bajos niveles de industrialización, y poniendo en comunicación a todos los agentes económicos implicados en el desarrollo de la comarca, conservando los valores históricos y naturales del territorio.

Las perspectivas de futuro para Aroche pueden ser similares a otros núcleos rurales del interior de Andalucía; no obstante, desde la administración municipal se han sentado las bases para intentar buscar alternativas de desarrollo ante el reto demográfico. La pandemia ha provocado cambios sociales muy importantes y cuyas consecuencias serán perceptibles a lo largo de los próximos años. Lamentablemente nos encontramos lejos de los grandes núcleos poblacionales, sedes de grandes empresas que generan una significativa masa susceptible de convertirse en teletrabajadores y por tanto candidatos a repobladores del mundo rural. Los cambios en este sentido surgidos por el Covid-19 no estimamos que puedan afectar al municipio, aunque sí es cierto que otras consecuencias ya son apreciables, como la preferencia por un turismo más rural, más natural y patrimonial, y menos masificado. $\mathrm{Y}$ a pesar de que se ha paralizado casi por completo el turismo de grupos, muy significativo antes en 
esta zona, se he registrado un considerable aumento del turismo familiar, no sólo en visitas, sino en pernoctaciones, lo que augura buenas perspectivas de futuro.

En la actualidad y aprovechando la llegada de los fondos Next Generation Aroche prepara numerosos proyectos donde el territorio, la sostenibilidad y el patrimonio están presentes como motor de desarrollo y lucha contra la despoblación. El Proyecto Patrimonio tendrá continuidad, nuevos planes que desarrollar, nuevos retos y esperemos que nuevos logros. Este modelo práctico, que ha bebido de otras praxis exitosas, y después de diecisiete años de existencia, podría ser una inspiración para otros pequeños municipios, aunque el objetivo sigue siendo trabajar por conservar el patrimonio y hacer partícipe a los vecinos y vecinas, porque el futuro de Aroche y el del proyecto dependerán de la sociedad.

\section{Bibliografía}

Alba Calzado, M. A. (2009): La Problemática en la gestión de las ciudades patrimonio Mundial: el caso del Conjunto Arqueológico de Mérida. Revista Patrimonio Cultural de España, N². Ministerio de Cultura: 233-249

- (2014): La difusión del Patrimonio Histórico-Arqueológico de Mérida al servicio del ciudadano (y viceversa). Hispania Nostra, $\mathrm{N}^{\circ} 14: 38-43$.

Almansa, J. (2011): Arqueología para todos los públicos. Hacia una definición de la Arqueología Pública ‘a la española'. ArqueoWeb 13: 87-107.

Ayán, X. (2014): El capital social del patrimonio arqueológico. La gestión para el desarrollo y la participación de las comunidades locales. El pasado en su lugar. Patrimonio arqueológico, desarrollo y turismo. Vives, J. y Ferrer, C. eds., Valencia: 139-176.

Ballart, J. (1997): El patrimonio histórico y arqueológico, valor y uso. Barcelona. Ariel.

Ballart, J.; Tresseras, J.J. (2001): Manual de Gestión del Patrimonio Histórico. Barcelona. Ariel.

Bermejo, J. (2014): Arucci y Turobriga, civitas et territorium: un modelo de implantación territorial y municipal en la Baeturia Celtica. Universidad de Huelva, Servicio de Publicaciones, 2014.

Bermejo, J.; Campos, J. M. (2009): La sala de los ediles de Arucci Turobriga. Officina Ponderaria Aruccitana. Saguntum 41. Valencia: 187-198.

- (2011): Il campus di Arucci Turobriga. Un nuovo esempio nelle provincie occidentali. ATTA, 21: 55-68.

- (2013): ¿Lex Municipalis Aruccitana? Una nueva interpretación para el fragmento de lex municipalis de Cortegana (Huelva). Latomus: revue d'éstudes latines, Vol. 72 No 2: 435-446.

Bermejo, J.; Gómez, A.; Campos, J. (2014): Urbanismo aruccitano: el trazado regulador de la domus norte. Revista d' Arqueología de Ponent 24: 41-50.

Campos Carrasco, J.M. (2009): El urbanismo del municipio romano de Turobriga (Aroche, Huelva). Estudio de prehistoria y arqueología en homenaje a Pilar Acosta Martínez. Coord. por Rosario CruzAuñón Briones y Eduardo Ferrer Albelda. Sevilla: 465-482.

Campos, JM.; Bermejo, J.; Medina, N. (2013): La ciudad de Arucci Turobriga y la implantación de Roma en el Norte del Territorio onubense. Arqueología en la provincia de Huelva. Homenaje a Francisco Javier Rastrojo Lunar: 221-234.

Campos, J.M.; Medina, N.; Bermejo, J. (2017): El modelo de investigación y gestión de la ciudad romana de Arucci (Aroche, Huelva). RESCATE, del Registro estratigráfico a la sociedad del conocimiento: el patrimonio arqueológico como agente de desarrollo sostenible. Vaquerizo, Ruiz y Delgado eds. UCOPress: 189-206.

Criado Boado, F. (1996a): El futuro de la arqueología, ¿la arqueología del futuro?. Trabajos de Prehistoria, 53 (1). Madrid: 13-26.

- (1996b): Hacia un modelo integrado de gestión de investigación y gestión del Patrimonio Histórico: La cadena interpretativa como propuesta. Boletín del Instituto Andaluz del Patrimonio Histórico, 16. Sevilla: 73-8.

Da Silva Rafael, L.I. (2010): Os Trinta anos do projecto Mértola Vila Museu: Balanço e Perspectivas. Traballo fin de Mestrado. V Curso de Mestrado em Museología. Departamento de Historia. Universidad de Évora.

Delgado, M.; Jaén, D. (2017): El conjunto arqueológico de Fuente Álamo (Puente Genil, Córdoba). Quince años de puesta en valor y gestión integral del patrimonio en el medio rural. RESCATE, del registro 
estratigráfico a la sociedad del conocimiento: el patrimonio arqueológico como agente de desarrollo sostenible. Vaquerizo, Ruiz y Delgado Eds. UCOpress: 223-256.

García Cuetos, P. (2012): El patrimonio Cultural. Conceptos básicos. Zaragoza. Prensas universitarias de Zaragoza.

García-Dils De La Vega, S. (2015): Colonia Augusta Firma Astigi. El urbanismo de la Écija romana y tardoantigua. Sevilla. Editorial Universidad de Sevilla, 570.

García-Dils De La Vega, S.; Ordoñez Agulla, S. (Ed.) (2011): Civitas Solis. Diez años de estudios sobre la ciudad antigua de Écija. Écija. Editorial Gráficas Sol.

Gómez-Martínez, S. (2008a): Coord. Alcáçova do Castelo de Mértola 1978-2008. Trinta anos de arqueologia. Mértola.

- (2008b): Mértola Vila Museu: patrimonio, rentabilidad y ciudadanía. El Patrimonio Arqueológico a debate: su valor cultural y económico. Actas de las Jornadas celebradas en Huesca en 2007: 83-99.

- (2017): Mertola, Vila Museu. Un proyecto cultural de desarrollo. RESCATE, del registro estratigráfico a la sociedad del conocimiento: el patrimonio arqueológico como agente de desarrollo sostenible. Vaquerizo, Ruiz y Delgado eds. UCOPress: 269-286.

Gómez, S.; Rafael, L.; Torres, C. (2016): Mértola Vila Museu: um projecto arqueológico de desenvolvimiento integrado. Revista de Arqueología Pública V.10 No. 3: 55-80.

Martín Guglielmino, M. (2007): La difusión del patrimonio. Actualización y debate. e-rph Revista Electrónica de Patrimonio Histórico, 1. Granada.

Medina Rosales, N. (2005): La fortificación de Aroche. Ayuntamiento de Aroche.

- (2010): Intervención Arqueológica Preventiva en el Yacimiento de La Ladrillera de Aroche (Huelva). Anuario Arqueológico de Andalucía 2006: 2122-2133.

- (2018a): La gestión integral del patrimonio histórico-arqueológico desde el ámbito municipal: el caso de Aroche. Arqueología y Territorio en la provincia de Huelva. Veinte años de las Jornadas de Aljaraque (1998-2017). Campos Jara ed. Diputación de Huelva: 515-538.

- (2018b): Gestión municipal del patrimonio histórico-arqueológico de Aroche: 10 años de desarrollo del Proyecto Patrimonio, 2004-2014. En Actas del VIII Encontro de Arqueologia do Sudoeste Peninsular. Serpa: 957-970.

- (2018c): Investigación, conservación y puesta en valor de la muralla de Aroche (Huelva) 2007-2014. VIII Encuentro de Arqueología del Suroeste Peninsular. Serpa: 777-794.

- (2020a): La gestión municipal del patrimonio: El caso de Aroche (Huelva), 14 años de desarrollo del Proyecto Patrimonio (2004-2018). 40 anos de investigação para o desenvolvimento. Revista Arqueología Medieval, $\mathrm{n}^{\circ}$ 15: 183-195

- (2020b): El Proyecto Patrimonio del Ayuntamiento de Aroche (Huelva) confirma la fórmula de la gestión local e integral. Revista PH $n^{\circ}$ 100, junio 2020: 6-9.

- (2020c): El patrimonio como motor de desarrollo social, cultural y económico en el ámbito rural: el modelo de Aroche (Huelva). Onoba, Revista de Arqueología y Antigüedad no 08: 2020.

- (2020d): El patrimonio Histórico y Cultural del Municipio de Aroche (Huelva): propuesta de un modelo de gestión. Arias Montano, Repositorio Institucional de la Universidad de Huelva, Tesis doctoral. (http://hdl.handle.net/10272/19149).

- (e.p.a): Intervención arqueológica de urgencia en Plaza del Plantel, Muralla de Aroche (Huelva). Anuario Arqueológico de Andalucía 2013.

- (e.p.b.): La socialización del patrimonio en Aroche (Huelva): el Festival de Diana y la Noche de las Velas. En Actas del X Encuentro de Arqueología del Suroeste Peninsular. Zafra 2018.

Medina, N.; González, L. y Acedo, P. (e.p.): Restauración e impermeabilización de la cubierta de la Iglesia de Nuestra Señora de la Asunción de Aroche (Huelva). XXVII Jornadas del Patrimonio de Comarca de la Sierra, Cañaveral de León, 2012.

Moreno, A.; Sariego, I. (2017): Relaciones entre turismo y arqueología. El turismo arqueológico. Pasos. Revista de Turismo y Patrimonio Cultural 15.1, Universidad de La Laguna: 163-180.

Muñiz Jaén, I. (2002): El Ecomuseo del Río Caicena en Almedinilla-Córdoba: un proyecto de desarrollo social, cultural y económico desde el patrimonio histórico y natural. IV Jornadas de Difusión del patrimonio Histórico. Sevilla. Junta de Andalucía: 205-227.

- (2007): El Proyecto municipal del ecomuseo del Río Caicena (Almedinilla, Córdoba): Patrimonio y desarrollo local desde el mundo rural. Revista e-rph. 
- (2008a): Una década gestionando el patrimonio cultural desde el Ecomuseo del Río Caicena (Almedinilla, Córdoba). La Gestión del Patrimonio Cultural: Apuntes y casos en el contexto rural andaluz. Coord. por Alonso, J.A. y Castellano, M. Granada: 137-150.

- (2008b): El Ecomuseo del Río Caicena (Almedinilla-Córdoba). Un proyecto de desarrollo rural desde el patrimonio histórico-natural. Revista digital para profesionales de la enseñanza $\mathrm{n}^{\circ} 5$ Temas para la Educación.

- (2008c): El Ecomuseo del Río Caicena (Almedinilla, Córdoba): un proyecto de desarrollo rural desde el patrimonio histórico-natural, ¿y la participación ciudadana?. Participación Ciudadana, patrimonio cultural y museos: entre la teoría y la praxis. Iñaki Arrieta Urbizberea ed. Universidad del País Vasco: 95-112.

- (2016): El Ecomuseo del río Caicena (Almedinilla, Córdoba). Revista Cuadiernu n ${ }^{\circ} 4$. La PonteEcomuséu: 101-109.

Pérez-Juez Gil, A. (2006): Gestión del Patrimonio Arqueológico. Barcelona. Ariel.

- (2010): La gestión del patrimonio arqueológico: de la tradición al nuevo panorama del siglo XXI. La ciudad dentro de la ciudad: la gestión y conservación del patrimonio arqueológico en ámbito urbano. Hidalgo, R. (Ed.), Sevilla: 23-40.

- (2017): Gestión e Investigación, de la utopía a la necesidad. RESCATE, del Registro estratigráfico a la sociedad del conocimiento: el patrimonio arqueológico como agente de desarrollo sostenible. Vaquerizo, Ruiz y Delgado eds. UCOPress: 89-108.

Pérez Macías, J.A.; Vidal Teruel, N.; Campos Carrasco, J.M.; Rastrojo Lunar, J.; Gómez, A.; Medina Rosales, N. (2002): Consolidación y Puesta en Valor del Forum de la ciudad hispanorromana de Turobriga (Aroche, Huelva). Anuario Arqueológico de Andalucía 1999: 356-365.

Pérez, J.A.; Campos, J.M.; Rodrigo, J.Ma.; Vidal, N.O. (1999): Ager y Municipium Aruccitanus. XII Jornadas de Patrimonio de la Sierra de Huelva. Aracena, 1997: 195-210.

Pérez, J.A.; Campos, J.M.; Vidal, N.O (1997): Arucci y Turobriga. El proceso de Romanización de Los Llanos de Aroche. Cuadernos de Prehistoria y Arqueología de la Universidad Autónoma de Madrid, 24. Madrid: 189-208.

Querol, M.A. (2010): Manual de Gestión del Patrimonio Cultural. Madrid. Akal.

Querol, M.A.; Martínez, B. (1996): La gestión del Patrimonio Arqueológico en España. Madrid. Alianza Editorial.

Rausell Köster, P. (2014): La sostenibilidad económica de los proyectos de desarrollo local basados en el patrimonio. El pasado en su lugar. Patrimonio arqueológico, desarrollo y turismo, en Vives, J. y Ferrer, C. (Eds.), Valencia: 5-28.

Rivera, T.; Romero, E. (2005): Proyecto de restauración del castillo de Aroche (Huelva). El enfoque interdisciplinar en la positivación de criterios de intervención: estudios arqueológicos. Actas de las Jornadas Los Castillos. Reflexiones ante el reto de su conservación. Alcalá la Real 26-28 de mayo de 2004: 217-230.

Ruiz Zapatero, G. (2017): Presente y futuro de la Arqueología en España. Luces, sombras y desafíos. RESCATE, del Registro estratigráfico a la sociedad del conocimiento: el patrimonio arqueológico como agente de desarrollo sostenible. Vaquerizo, Ruiz y Delgado eds. UCOPress: 53-76.

Torres, C. (2003): Campo Arqueológico de Mértola (Portugal). Incentivar un turismo rural a escala humana. Boletin-Revista del IAPH, $n^{\circ} 42$. Sevilla.

Torres, C.; Gómez, S. (2007): Mértola Vila Museu. Un proyecto cultural de desarrollo integrado. mus-A Revista de los Museos de Andalucía $\mathrm{n}^{\circ}$ 8. Museos locales: naturaleza y perspectivas: 91-99.

Vaquerizo Gil, D. (2016): Arqueología Somos Todos o el triunfo de Sísifo. RESCATE. Del registro estratigráfico a la sociedad del conocimiento. Vaquerizo, D., Ruiz, A. y Delgado, M. Eds. Córdoba, Vol. I.: 155-188.

- (2017): Arqueología Pública, o el uso social del Patrimonio. Revista Otarq 2, Madrid: 251-284.

- (2018): Detectives del tiempo...Reflexiones sobre pasado, presente y futuro de la Arqueología en España. Complutum 29 (1): 13-36.

Vidal, N.O; Medina, N.; Domínguez, E. (e.p.): Intervención arqueológica de urgencia en el hotel Casa Palacio Conde del Álamo de Aroche (Huelva). Anuario Arqueológico de Andalucía 2019. 
